\title{
Experiment and Analysis of Wedge Cutting Angle on Cutting Effect
}

\author{
Deqiang Yang, ${ }^{1,2}$ Xuguang Wang, ${ }^{2}$ Yinjun Wang, ${ }^{2}$ Huaming An $\mathbb{D}^{3}$, and Zhen Lei $^{4}$ \\ ${ }^{1}$ School of Civil and Resource Engineering, University of Science and Technology Beijing, Beijing 100083, China \\ ${ }^{2}$ BGRIMM Technology Group, Beijing 100160, China \\ ${ }^{3}$ Faulty of Public Security and Emergency Management, Kunming University of Science and Technology, Kunming 650093, China \\ ${ }^{4}$ Guizhou Institute of Technology, Guiyang 550003, China \\ Correspondence should be addressed to Huaming An; huaming.an@yahoo.com
}

Received 4 January 2020; Accepted 23 April 2020; Published 28 May 2020

Academic Editor: Xueping Fan

Copyright (C) 2020 Deqiang Yang et al. This is an open access article distributed under the Creative Commons Attribution License, which permits unrestricted use, distribution, and reproduction in any medium, provided the original work is properly cited.

\begin{abstract}
In the process of tunnel excavation, large charge wedge cutting blasting is widely used to improve the effect of cut blasting and speed up the excavation rate, which is tantamount to increasing the construction cost. In order to save economic cost and improve cutting blasting effect, wedge cutting models with five different cutting angles were experimented and studied by using concrete materials on the basis of similarity theory analysis. The relationships among cutting depth, blasting volume, blasting fragment, and cutting angle are studied and deduced by the dimensional analysis method. The polynomial fitting of cutting depth, blasting volume, blasting fragment, and cutting angle is carried out according to the experimental data, and the corresponding fitting formula is obtained. The optimum cutting depth, hole utilization rate, blasting volume, and blasting fragment were obtained when the wedge cutting angle was $67^{\circ}$ under the same charge. The values were $1.665 \times 10^{-1} \mathrm{~m}, 92.5 \%, 8.390 \times 10^{-3} \mathrm{~m}^{3}$, and $49.07 \mathrm{~mm}$, respectively. With the use of TC4850N type blasting vibration meter, the blasting vibrations on the wedge in four directions are tested and analyzed. The results show that when wedge cutting inclination is 65 degrees, the peak vibration velocity is the minimum and the vibration intensity of the wedge cutting inclined side is generally smaller than that of the vertical side. Considering the cutting depth, blasting volume, blasting fragment, blasting vibration hazard, drilling error, tunneling construction cost, and other factors, the $65^{\circ} \sim 69^{\circ}$ wedge cutting blasting in engineering practice can improve the blasting tunneling rate and increase economic benefits. The experimental results show that the blasting tunneling rate is increased and the economic benefit is increased with the minimum construction tunneling cost, which has certain engineering significance.
\end{abstract}

\section{Introduction}

With the rapid progress of modernization, the construction of high-speed railways, freeways, and underground rock projects has grown rapidly. Currently, drilling and blasting methods are still the main methods of tunnel and underground rock space excavation. More than $95 \%$ of mountain tunnels are formed using drilling and blasting in China [1]. Cutting blasting is key to creating another free surface for subsequent blasting and influences the overall blasting procedure [2]. Wedge cuttings have the advantages of few boreholes, easy rock casting, and low drilling accuracy requirements; thus, these cuttings have been widely used in hard rock excavation. Langefors and Kihlstrom [3] studied cut blasting earlier and proposed some cutting patterns.
Shapiro [4] compared wedge cuttings with other cuttings and believed that wedge cuttings ensured maximum efficiency in soft rock with relatively shallow blast holes, that is, shallower than $2.5 \mathrm{~m}$. Cardu and Seccatore [5] offered statistics of industrial trends in which wedge cuttings appeared to be adopted in a wider variety of applications.

Based on the above analysis, wedge cutting blasting technology is often used in tunnel excavation construction, and the key to improving excavation speed and blasting efficiency lies in the selection of wedge cutting angle. The best cutting angle determines the quality of the whole blasting construction, the tunneling effect, and even the progress of each tunneling cycle. References $[6,7]$ used fuzzy comprehensive evaluation theory to analyze and studied the cutting methods and parameters commonly used in tunnel 
excavation. Dai et al. [8] divided the formation process of groove cavity after triangular column straight hole cutting blasting into rock destruction stage and broken rockthrowing stage. Zhang et al. [9] studied the cutting blasting in the medium-deep hole blasting of rock-roadway and obtained the most suitable cutting method. Liu et al. [10] adopted a multirow one-way cutting method in the excavation construction of shaft and roadway, and the blasting effect was good. Pei et al. [11] determined a series of blasting parameters of double-wedge cutting mode through theoretical analysis. In the wedge cutting symmetrical blasting model experiments, Liang et al. [12] used RDX explosive to test cement mortar test blocks, and the blasting effects such as groove depth, volume, and hole utilization rate formed by blasting were comprehensively evaluated and analyzed. On the basis of on-site investigation and theoretical analysis, through wedge cutting blasting tests, Chu et al. [13] showed that the change of cutting hole inclination angle would seriously affect the utilization rate of blast hole, the depth of groove cavity, and the volume of groove cavity, especially when the inclination angle is asymmetric. Xiong et al. [14] applied the analytic hierarchy process to analyze various factors affecting wedge cutting blasting and concluded that the main factor affecting cutting blasting is the inclination angle of the blast hole. In the blasting model test research of different cutting methods, Yuan et al. [15] discovered that the wedge millisecond blasting can improve the utilization rate of blast holes and cutting volume. Pu et al. [16] used grey correlation theory to carry out grey correlation analysis on various factors affecting wedge cutting blasting and concluded that the biggest factor affecting cutting blasting is hole inclination angle. $\mathrm{Hu}$ et al. [17] adopted the joint modeling technology of AUTO CAD and ANSYS to conclude that the volume of vertical single-wedge cutting is larger than that of straight hole barrel cutting. Zhang et al. [18] concluded that the second-order and second-stage cutting is superior to the common wedge cutting technology. In references $[19,20]$, the cutting parameters are optimized and analyzed by numerical simulation. It is concluded that the blasting footage decreases obviously with the increase of cutting angle. Sun et al. [21] investigated the influence of the slant angle on cutting force and rock fracture pattern, and two new findings were made: (1) the rotational angle of the groove cut by a tilted pick was possibly different from the tilt angle and (2) all forces on a pick increased significantly with the increase of the slant angle. The findings of this study can help improve the rock cutting efficiency. Man et al. [22] found that the rock slag size of single-wedge and doublewedge cutting is uniform, which is beneficial to slag extraction. Moreover, the blasting vibration velocity and blasting energy have been analyzed. It is found that the energy distribution of single-wedge and double-wedge cutting is more uniform, mainly concentrated in the highfrequency part, while the energy of straight parallel hole cutting is more concentrated in the low-frequency part.

Wedge cutting is the most common blasting excavation method because the number of drilling holes is small and the requirement for drilling accuracy is not high. It is easier to give full play to its advantages when cooperating with bench construction. However, its excavation efficiency needs to be studied when different cutting angles change. Due to that the results of field cutting tests are not easy to be statistically analyzed, this paper used concrete as similar materials to systematically and deeply study the wedge cutting depth, blasting volume, blasting fragment, and blasting vibrations with different cutting angles, to put forward the optimal wedge cutting angle, which is of great significance to guide engineering practice, improve tunnel excavation blasting efficiency, and save excavation cost.

\section{Theoretical Analysis}

2.1. Similarity of Model Experiments. Geometric similarity constant, material similarity constant, and blasting dynamic similarity constant are selected from the similarity law of tunnel excavation wedge cutting blasting model experiments and the similarity constant of model experiments.

2.1.1. Geometric Similarity. Considering the experiment conditions, the model size should not be too large and the model boundary effect, the model experiment, determines that the geometric size ratio of the prototype to the model of wedge cutting is 15 . Due to the reasons of charging and placing detonators, the diameter of the model blast hole should be $10 \mathrm{~mm}$, while the diameter of the prototype blast hole is generally $45 \mathrm{~mm}$, so the diameter ratio of the prototype blast hole to the model blast hole is 4.5 . Although there are some differences with the requirements of geometric similarity, when the length-diameter ratio of the blast hole is large $\left(L / d_{b}>10\right)$, it has little influence on the test results $[23,24]$.

2.1.2. Material Similarity. In the process of carrying out model experiments, scholars at home and abroad generally use concrete materials to carry out rock blasting model experiments because it is difficult to find model materials that are completely consistent with the site rock mass conditions [25]. In this paper, concrete materials were also used to prepare wedge cutting models with various angles for blasting experiments.

2.1.3. Similarity of Blasting Power. The diameter of the blast hole in the model is $10 \mathrm{~mm}$, which is less than the critical diameter of emulsion explosive used in tunnel blasting onsite. Therefore, the simple substance high explosive Tai'an is used as the model explosive in the experiment and the No. 8 detonator is used for initiation.

\subsection{Prediction Dimensional Analysis of Blasting Index.} Cutting depth $H$, blasting volume $V$, and blasting fragment $D$ are the main indexes to evaluate the blasting effect of wedge cutting at different angles, which are mainly affected by explosive quantity $Q$, explosive density $\rho_{c}$, concrete strength $\sigma_{m}$, vertical depth of blast holes $h$, hole spacing $b_{1}$, and hole bottom spacing $b_{2}$. 
The above three main indexes for evaluating the blasting effect of wedge cutting at different angles are written as follows:

$$
\begin{aligned}
& H=f\left(Q, \rho_{c}, \sigma_{m}, h, b_{1}, b_{2}\right), \\
& V=f\left(Q, \rho_{c}, \sigma_{m}, h, b_{1}, b_{2}\right), \\
& D=f\left(Q, \rho_{c}, \sigma_{m}, h, b_{1}, b_{2}\right) .
\end{aligned}
$$

See Table 1 for the dimensions of each physical quantity in the equation.

Taking the vertical depth of the blast hole $h$, the explosive quantity $Q$, and the concrete strength $\sigma_{m}$ as the basic physical quantities, according to the $\pi$ theorem, the above relation can be expressed as follows:

$$
\begin{aligned}
& \pi_{H}=f\left(\pi_{\rho_{c}}, \pi_{b_{1}}, \pi_{b_{2}}\right), \\
& \pi_{V}=f\left(\pi_{\rho_{c}}, \pi_{b_{1}}, \pi_{b_{2}}\right), \\
& \pi_{D}=f\left(\pi_{\rho_{c}}, \pi_{b_{1}}, \pi_{b_{2}}\right) .
\end{aligned}
$$

For cutting depth $H$,

$$
\pi_{H}=\frac{H}{h^{\alpha} Q^{\beta} \sigma_{m}^{\gamma}},
$$

where $\alpha, \beta$, and $\gamma$ are undetermined coefficients; because $\pi$ is dimensionless quantities, the dimensions of the numerator and denominator should be equal, that is,

$$
[H]=[h]^{\alpha}[Q]^{\beta}\left[\sigma_{m}\right]^{\gamma} .
$$

Substituted dimensions are

$$
[L]=[L]^{\alpha}[M]^{\beta}\left[M L^{-1} T^{-2}\right]^{\gamma}
$$

Thus, the solution is $\alpha=1, \beta=\gamma=0$.

So we can get

$$
\pi_{H}=\frac{H}{h} .
$$

The same process can be

$$
\begin{aligned}
& \pi_{V}=\frac{V}{h^{3}}, \\
& \pi_{D}=\frac{D}{h}, \\
& \pi_{\rho_{c}}=\frac{\rho_{c}}{h^{-3} Q}, \\
& \pi_{b_{1}}=\frac{b_{1}}{h}, \\
& \pi_{b_{2}}=\frac{b_{2}}{h} .
\end{aligned}
$$

Then the cutting depth $H$, the blasting volume $V$, and the blasting fragment $D$ can be expressed as
TABLE 1: Blasting physical dimension.

\begin{tabular}{lcc}
\hline Physical quantity & Symbols & Dimension \\
\hline Cutting depth & $H$ & $L$ \\
Blasting volume & $V$ & $L^{3}$ \\
Blasting fragment & $D$ & $L$ \\
Explosive quantity & $Q$ & $M$ \\
Explosive density & $\rho_{c}$ & $M L^{-3}$ \\
Concrete strength & $\sigma_{m}$ & $M L^{-1} T^{-2}$ \\
Hole vertical depth & $h$ & $L$ \\
Orifice spacing & $b_{1}$ & $L$ \\
Hole bottom spacing & $b_{2}$ & $L$ \\
\hline
\end{tabular}

$$
\begin{aligned}
& \pi_{H}=\frac{H}{h}=f\left(\frac{\rho_{\mathrm{c}}}{h^{-3} Q}, \frac{b_{1}}{h}, \frac{b_{2}}{h}\right), \\
& \pi_{V}=\frac{V}{h^{3}}=f\left(\frac{\rho_{\mathrm{c}}}{h^{-3} Q}, \frac{b_{1}}{h}, \frac{b_{2}}{h}\right), \\
& \pi_{D}=\frac{D}{h}=f\left(\frac{\rho_{\mathrm{c}}}{h^{-3} Q}, \frac{b_{1}}{h}, \frac{b_{2}}{h}\right) .
\end{aligned}
$$

In the experiment, the explosive is Tai' an, the charge is fixed, the vertical depth of the blast hole and the distance between the orifices are also fixed, and the concrete model is of the same material and the same proportion. Therefore, the following parameters are constants in the experiment process, namely, the explosive quantity $Q$, explosive density $\rho_{c}$, concrete strength $\sigma_{m}$, vertical depth of the blast hole $h$, and the distance between the orifices $b_{1}$. Equations (8)-(10) can be changed to

$$
\begin{aligned}
& \frac{H}{h}=f\left(\frac{b_{2}}{h}\right), \\
& \frac{V}{h^{3}}=f\left(\frac{b_{2}}{h}\right), \\
& \frac{D}{h}=f\left(\frac{b_{2}}{h}\right) .
\end{aligned}
$$

That is,

$$
\begin{aligned}
& H=\phi\left(\frac{b_{2}}{h}\right), \\
& V=\phi\left(\frac{b_{2}}{h}\right), \\
& D=\phi\left(\frac{b_{2}}{h}\right) .
\end{aligned}
$$

In equations (12)-(14), the cutting depth $H$, blasting volume $V$, and blasting fragment $D$ change with the hole bottom spacing $b_{2}$.

In Figure 1, $\theta=\operatorname{arc} \cot \left(b_{1}-b_{2} / 2 h\right)$, the vertical depth of the blast hole and the distance between the orifices are fixed. 


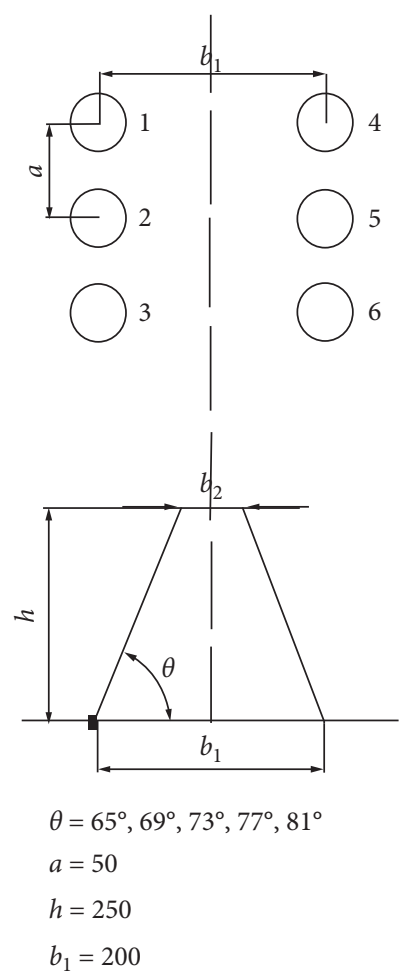

Figure 1: Layout of single-stage wedge cutting blast holes with different angles (unit: $\mathrm{mm}$ ).

Therefore, the change of hole bottom spacing $b_{2}$ leads to the change of the wedge cutting hole angle $\theta$.

Therefore, set

$$
\begin{aligned}
& x=\frac{b_{2}}{h} \propto \theta, \\
& H=\phi\left(\frac{b_{2}}{h}\right)=\phi(x), \\
& V=\phi\left(\frac{b_{2}}{h}\right)=\phi(x), \\
& D=\phi\left(\frac{b_{2}}{h}\right)=\phi(x) .
\end{aligned}
$$

Since the function equation is an elementary function, it is analytical; that is, it can be derived indefinitely in the domain. According to Taylor's theorem, if a function $\phi$ has a continuous derivative up to $n$ order in a neighborhood of a point $x_{0}$, then

$$
\begin{aligned}
\phi(x) & =\phi\left(x_{0}\right)+\phi^{\prime}\left(x_{0}\right)\left(x-x_{0}\right)+\frac{\phi^{\prime \prime}\left(x_{0}\right)}{2 !}\left(x-x_{0}\right)^{2} \\
& +\cdots+\frac{\phi^{(n)}\left(x_{0}\right)}{n !}\left(x-x_{0}\right)^{n}+R_{n}(x),
\end{aligned}
$$

The above equation is Taylor's equation of $\phi$ at the point $x_{0}$, where $R_{n}(x)$ is Lagrange remainder; that is,

$$
R_{n}(x)=\frac{\phi^{(n+1)}(\xi)}{(n+1) !}\left(x-x_{0}\right)^{n+1}
$$

where $\xi$ is between $x$ and $x_{0}$.

Set $x_{0}=0$, the Taylor equation at this time can be transformed into

$$
\phi(x)=\phi(0)+\phi^{\prime}(0) x+\frac{\phi^{\prime \prime}(0)}{2 !} x^{2}+\cdots+\frac{\phi^{(n)}(0)}{n !} x^{n}+R_{n}(x) \text {. }
$$

In this case, the Lagrange remainder is

$$
R_{n}(x)=\frac{\phi^{(n+1)}(\xi)}{(n+1) !} x^{n+1}
$$

where $\xi$ is between $x$ and $x_{0}$.

When $n=4$,

$$
\begin{aligned}
\phi(x)= & \phi(0)+\phi^{\prime}(0) x+\frac{\phi^{\prime \prime}(0)}{2 !} x^{2}+\frac{\phi^{(3)}(0)}{3 !} x^{3}+\frac{\phi^{(4)}(0)}{4 !} x^{4} \\
& +R_{4}(x), \\
R_{4}(x)= & \frac{\phi^{(5)}(\xi)}{(5) !} x^{5},
\end{aligned}
$$

where $\xi$ is between $x$ and $x_{0}$.

If the coefficients are replaced by $A_{0}\left(B_{0}, C_{0}\right), A_{1}\left(B_{1}, C_{1}\right)$, $A_{2}\left(B_{2}, C_{2}\right), A_{3}\left(B_{3}, C_{3}\right), A_{4}\left(B_{4}, C_{4}\right)$, respectively, then equations (12)-(14) can be reduced to

$$
\begin{aligned}
& H=A_{0}+A_{1}(\theta)+A_{2}(\theta)^{2}+A_{3}(\theta)^{3}+A_{4}(\theta)^{4}+R_{4}(\theta) \\
& V=B_{0}+B_{1}(\theta)+B_{2}(\theta)^{2}+B_{3}(\theta)^{3}+B_{4}(\theta)^{4}+R_{4}(\theta) \\
& D=C_{0}+C_{1}(\theta)+C_{2}(\theta)^{2}+C_{3}(\theta)^{3}+C_{4}(\theta)^{4}+R_{4}(\theta) .
\end{aligned}
$$

In the equations $R_{4}(\theta)=\left(\phi^{(5)}(\xi) /(5) !\right) \theta^{5}, \xi$ is between $x$ and $x_{0}$.

When fitting the equation, the Lagrange remainder can be discarded first, and then the error of the fitting equation can be calculated. If the error is within the allowable range, it means that the removal of Lagrange remainder has no effect on the equation.

From equations (21)-(23), it can be seen that under the premise that only the explosion energy (regardless of the influence of gravity and other forces) and the medium properties do not change with the change of loading speed when the charge with the same charge quantity and the same charge density explodes in the same medium, the cutting depth $H$, the blasting volume $V$, and the blasting fragment $D$ change with the angle $\theta$ of the wedge cutting hole.

\section{Model Experiment Program and Fabrication}

3.1. Model Program. On the basis of analyzing and summarizing the existing research results, in order to reduce the number of experiments, a typical program method is 
proposed to carry out blasting experiments on single-stage wedge cutting under different cutting angles, as shown in Figure 1. In this model experiment, five wedge cutting angles with different cutting angles will be taken as the main factors to study and select wedge cutting with appropriate angles under the same explosive quantity.

3.2. Fabrication of Model Specimens. Based on the actual tunnel excavation cutting blasting as the prototype, the model experiment program is designed. The concrete model specimen is made, and the method of reserving the diameter of the blast hole in the concrete model specimen is designed. Five wedge cutting blast hole arrangements with different cutting angles $\left(65^{\circ}, 69^{\circ}, 73^{\circ}, 77^{\circ}\right.$, and $\left.81^{\circ}\right)$ are designed.

Considering the boundary effect of the model, the size of the model specimen in this experiment is $1200 \mathrm{~mm} \times 1200 \mathrm{~mm} \times 400 \mathrm{~mm}$. Ten model specimens were made with a hole diameter of $10 \mathrm{~mm}$ and a vertical depth of $200 \mathrm{~mm}$.

The experiment model is made of concrete pouring, and the material and proportion of the model are as follows: the cement is $42.5 \mathrm{R}$ ordinary Portland cement, the coarse aggregate is stones, the maximum particle size is not more than $2 \mathrm{~cm}$, and the particle size of river sand is less than $1 \mathrm{~mm}$. The mix proportion is cement: stone: river sand: water $=52: 88$ : $63: 21$ (weight ratio).

Due to the large size of the model specimen, in order to prevent the mould from being extruded and expanded by concrete, the experimental mould adopts a hole positioning mould formed by welding steel bars and steel plates. In order to reduce bubbles in the model and ensure the strength of the model, concrete needs to be vibrated and tamped while pouring.

In order to reserve blast holes while firing concrete specimens, a self-designed blast hole positioning mould is adopted. Wedge cutting angle control requires more accuracy. In order to ensure the accuracy of blast holes, an inclination angle controller is designed, as shown in Figure 2. After insertion, gently rotate and pull out the steel bars in the concrete every $1 \mathrm{~h} \sim 3 \mathrm{~h}$ to prevent the steel bars from solidifying in the concrete until the model hardens to form the required hole gun.

After the clay concrete specimen is hardened, the steel bar is pulled out, and the plastic film is rolled into a cone to block the blast hole to prevent debris, water, and so forth from falling into the blast hole and affecting the quality of the blast hole. The model specimen shall be made, covered with felt cloth and regularly sprinkled with water to maintain the specimen for not less than 28 days to ensure that the coagulated specimen meets the predetermined strength requirements. Figure 3 shows the clay concrete specimens.

According to the Standard for Test Methods of Mechanical Properties of Ordinary Concrete (GB50081-2002), when pouring the concrete model, take the concrete from the same batch of concrete to make three standard test blocks of $150 \mathrm{~mm} \times 150 \mathrm{~mm} \times 150 \mathrm{~mm}$ each for compressive strength test, splitting tensile strength test and longitudinal wave velocity test of ordinary concrete, and three standard test blocks of $150 \mathrm{~mm} \times 150 \mathrm{~mm} \times 300 \mathrm{~mm}$ each for axial compressive

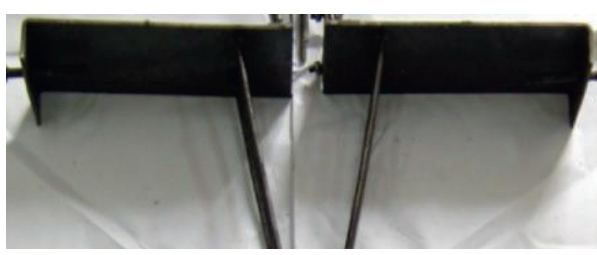

FIgURE 2: Cutting hole positioning diagram.

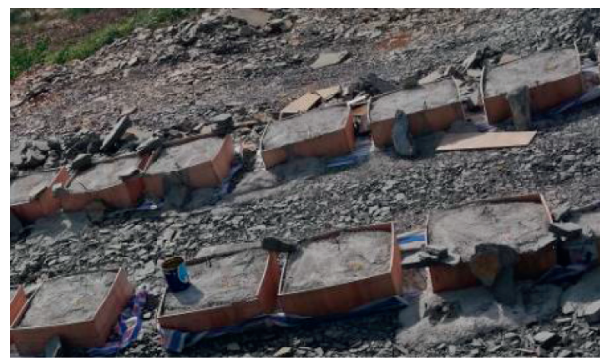

FiguRE 3: Forming of concrete specimens.

strength test, and static compressive modulus of elasticity test, and maintain for 28 days. After that, the static mechanical properties of the concrete model used in the blasting test will be tested. The standard model is shown in Figure 4.

The statistics of the test results of the mechanical properties of ordinary concrete measured in the laboratory are shown in Table 2.

3.3. Model Experiment Blasting Parameters. The parameters of each model experiment program are shown in Table 3.

3.4. Model Blasting Experiment. Each group of cutting mode has 2 blasting model specimens, with a total of 5 groups of cutting modes and 10 blasting model specimens. Each charging hole shall be filled with $1 \mathrm{~g}$ Tai'an explosive, the detonator tube shall be connected for the initiation, the blast holes shall be blocked by quick-drying cement, the explosive slag shall be removed after the explosion, and the cutting depth, the volume of the blasting room, and the blasting fragment shall be measured. The effect of blasting model experiment is shown in Figure 5. It can be seen that the I-5, II-6, I-7, I-8 model of postexplosion test is complete, and the cut part is thrown out to form a certain volume of the cavity, which does not affect the position of blasting vibration measuring point. The model of test I-9 is split into two parts along the direction of blast hole, and the cut part is only shaped through the crack and not thrown out.

\section{Analysis of Cutting Effect}

Cutting depth, hole utilization rate, blasting volume, and blasting fragment are important indexes to evaluate blasting effect. After each experiment, the depth of blasting cutting, the utilization rate of blast holes, the blasting volume, and the blasting fragment are counted. The relevant indexes of each model after blasting are shown in Table 4. 


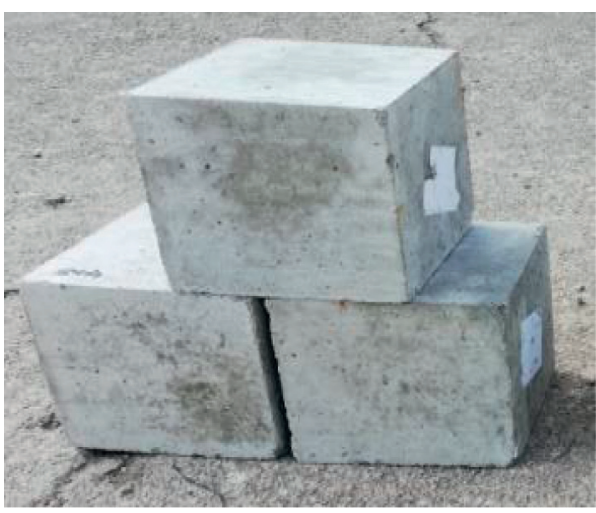

(a)

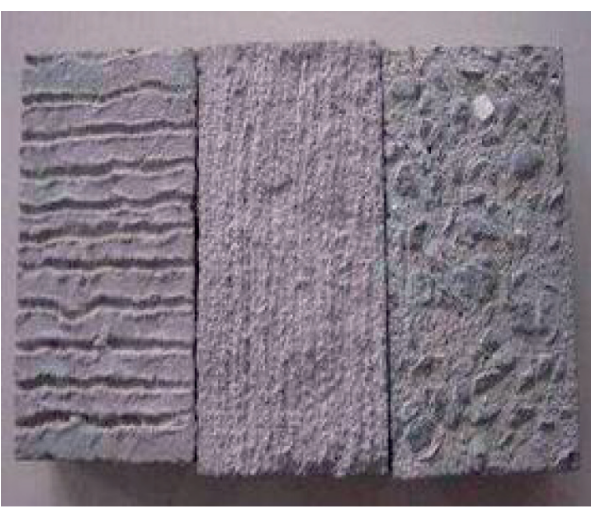

(b)

Figure 4: Standard model of concrete test block. (a) Test blocks of $150 \mathrm{~mm} \times 150 \mathrm{~mm} \times 150 \mathrm{~mm}$. (b) Test blocks of $150 \mathrm{~mm} \times 150 \mathrm{~mm} \times 300 \mathrm{~mm}$.

TABLE 2: Test results of mechanical properties of ordinary concrete.

\begin{tabular}{lc}
\hline Density $\left(\mathrm{kg} / \mathrm{m}^{3}\right)$ & 2405.35 \\
\hline Compressive strength $(\mathrm{MPa})$ & 43.00 \\
Splitting tensile strength $(\mathrm{MPa})$ & 2.34 \\
Axial compressive strength $(\mathrm{MPa})$ & 36.11 \\
Static compressive modulus of elasticity $(\mathrm{GPa})$ & 37.27 \\
Longitudinal wave velocity $(\mathrm{m} / \mathrm{s})$ & 4025 \\
\hline
\end{tabular}

TABLE 3: Blasting model experiment program.

\begin{tabular}{|c|c|c|c|c|c|c|c|c|}
\hline $\begin{array}{l}\text { Cutting } \\
\text { mode }\end{array}$ & $\begin{array}{l}\text { Specimen } \\
\text { no. }\end{array}$ & $\begin{array}{l}\text { Aperture } \phi \\
\quad(\mathrm{mm})\end{array}$ & $\begin{array}{c}\text { Row spacing } \\
a(\mathrm{~mm})\end{array}$ & $\begin{array}{l}\text { Hole distance } \\
b_{1}(\mathrm{~mm})\end{array}$ & $\begin{array}{c}\text { Hole bottom } \\
\text { distance } b_{2}(\mathrm{~mm})\end{array}$ & $\begin{array}{l}\text { Hole vertical } \\
\text { depth } h(\mathrm{~mm})\end{array}$ & $\begin{array}{l}\text { Hole length } \\
\quad l(\mathrm{~mm})\end{array}$ & $\begin{array}{l}\text { Ultra-deep } \\
\text { depth } \Delta h \\
\quad(\mathrm{~mm})\end{array}$ \\
\hline $\begin{array}{l}65^{\circ} \text { wedge } \\
\text { cutting }\end{array}$ & I-5, II-5 & 10 & 50 & 200 & 13 & 200 & 221 & 20 \\
\hline $\begin{array}{l}69^{\circ} \text { wedge } \\
\text { cutting }\end{array}$ & I-6, II-6 & 10 & 50 & 200 & 46 & 200 & 214 & 20 \\
\hline $\begin{array}{l}73^{\circ} \text { wedge } \\
\text { cutting }\end{array}$ & I-7, II-7 & 10 & 50 & 200 & 78 & 200 & 209 & 20 \\
\hline $\begin{array}{l}77^{\circ} \text { wedge } \\
\text { cutting }\end{array}$ & I-8, II-8 & 10 & 50 & 200 & 108 & 200 & 205 & 20 \\
\hline $\begin{array}{l}81^{\circ} \text { wedge } \\
\text { cutting }\end{array}$ & I-9, II-9 & 10 & 50 & 200 & 137 & 200 & 202 & 20 \\
\hline
\end{tabular}

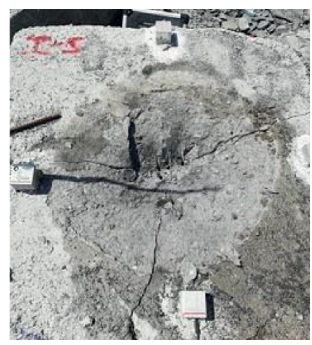

(a)

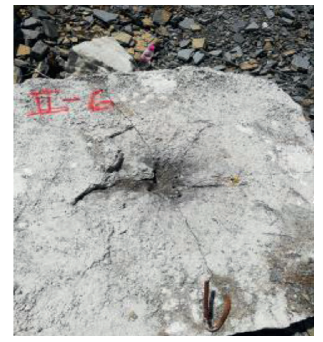

(b)

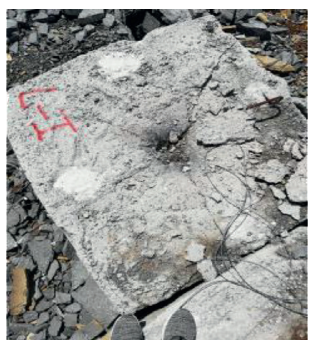

(c)

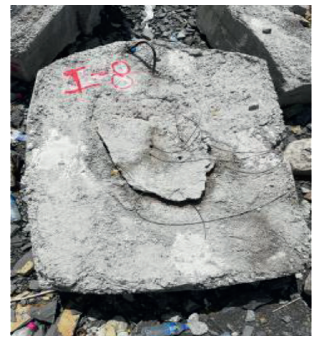

(d)

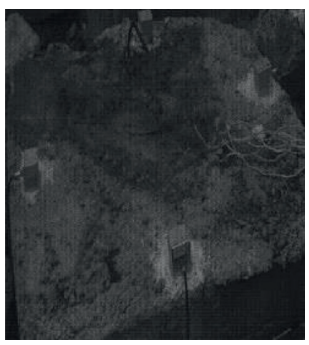

(e)

Figure 5: Experiment results of wedge cutting blasting with different angles. (a) $65^{\circ}$ wedge cutting, (b) $69^{\circ}$ wedge cutting, (c) $73^{\circ}$ wedge cutting, (d) $77^{\circ}$ wedge cutting, and (e) $81^{\circ}$ wedge cutting. 
TABLE 4: Statistical table of relevant indexes of blasting experiment.

\begin{tabular}{lccccccc}
\hline $\begin{array}{l}\text { Cutting } \\
\text { mode }\end{array}$ & $\begin{array}{c}\text { Specimen } \\
\text { no. }\end{array}$ & $\begin{array}{c}\text { Hole vertical } \\
\text { depth }\left(10^{-1} \mathrm{~m}\right)\end{array}$ & $\begin{array}{c}\text { Ultra-deep } \\
\text { depth } \\
\left(10^{-1} \mathrm{~m}\right)\end{array}$ & $\begin{array}{c}\text { Cutting } \\
\text { depth } \\
\left(10^{-1} \mathrm{~m}\right)\end{array}$ & $\begin{array}{c}\text { Utilization rate of } \\
\text { blast holes }(\%)\end{array}$ & $\begin{array}{c}\text { Blasting } \\
\text { volume } \\
\left(10^{-3} \mathrm{~m}^{3}\right)\end{array}$ & $\begin{array}{c}\text { Blasting } \\
\text { fragment } \\
(\mathrm{mm})\end{array}$ \\
$\begin{array}{l}65^{\circ} \text { wedge } \\
\text { cutting }\end{array}$ & I-5 & 2.000 & 0.200 & 1.530 & 85.0 & 7.410 & $\begin{array}{c}\text { Bulk } \\
\text { rate }(\%)\end{array}$ \\
$\begin{array}{l}69^{\circ} \text { wedge } \\
\text { cutting }\end{array}$ & II-6 & 2.000 & 0.200 & 1.611 & 89.5 & 8.215 & 54.72 \\
$\begin{array}{l}73^{\circ} \text { wedge } \\
\text { cutting }\end{array}$ & I-7 & 2.000 & 0.200 & 1.422 & 79.0 & 7.165 & 57.54 \\
$\begin{array}{l}77^{\circ} \text { wedge } \\
\text { cutting }\end{array}$ & I-8 & 2.000 & 0.200 & 1.188 & 66.0 & 5.920 & 86.06 \\
$\begin{array}{l}81^{\circ} \text { wedge } \\
\text { cutting }\end{array}$ & I-9 & 2.000 & 0.200 & 0.000 & 0.00 & 0.000 & 66.24 \\
\hline
\end{tabular}

4.1. Measurement of Model Cutting Depth. After each blasting experiment, remove the fragments falling around the groove cavity opening, delimit the boundary of the groove cavity opening, then take the center of the straighteye connection line of the two auxiliary centers before blasting as the center, measure the cutting depths in 8 different directions at intervals of $45^{\circ}$, and then take the average value of these depths as the cutting depth of this experiment, as shown in Figure 6.

For the sake of intuition, the cutting depth data in Table 4 can be obtained by fitting equation (21).

$$
\begin{aligned}
H= & -4882.519028+272.701066 \theta-5.704857 \theta^{2} \\
& +0.053004 \theta^{3}-0.000185 \theta^{4} .
\end{aligned}
$$

As can be seen from Table 5, the maximum absolute error of blasting cutting depth is $-0.013 \times 10^{-1} \mathrm{~m}$, and the maximum relative error is $1.09 \%$, which indicates that the error is relatively small. Within the allowable range, the fitting value is very close to the measured value, and the curve fitting is good.

From equation (24), the cutting depth of $67^{\circ}$ wedge cutting model experiment can be calculated as the optimal value, with a cutting depth value of $1.665 \times 10^{-1} \mathrm{~m}$ and a hole utilization rate of $92.5 \%$, as shown in Figure 7 .

4.2. Measurement of Model Blasting Volume. After each experiment, dry fine sand is filled into the plastic film above the tank cavity so that the fine sand is flush with the horizontal plane of the model. The volume of the recovered fine sand measured by the dosage cylinder is the volume of the blasting room after blasting. The volume measurement of the blasting room is shown in Figure 8.

For the sake of intuition, the blasting volume data in Table 4 can be obtained by fitting equation (22).

$$
\begin{aligned}
V= & -26874.777744+1494.679753 \theta-31.139147 \theta^{2} \\
& +0.288138 \theta^{3}-0.000999 \theta^{4} .
\end{aligned}
$$

As can be seen from Table 6, the maximum absolute error of blasting volume is $0.035 \times 10^{-3} \mathrm{~m}^{3}$, and the maximum

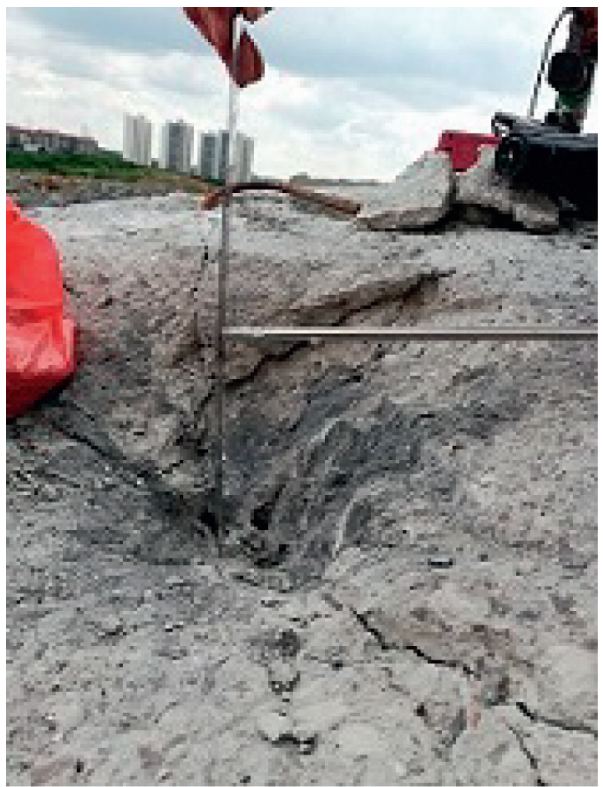

FIGURE 6: Cutting depth measurement.

TABLE 5: Error analysis table of cutting depth fitting formula.

\begin{tabular}{lcccc}
\hline $\begin{array}{l}\text { Cutting } \\
\text { angle }\end{array}$ & $\begin{array}{c}H \text { (measured } \\
\text { value) }\left(10^{-1} \mathrm{~m}\right)\end{array}$ & $\begin{array}{c}H^{*} \text { (fitting } \\
\text { value) } \\
\left(10^{-1} \mathrm{~m}\right)\end{array}$ & $H-H^{*}$ & $\begin{array}{c}\text { Relative } \\
\text { error }(\%)\end{array}$ \\
\hline $65^{\circ}$ & 1.530 & 1.537 & -0.007 & 0.46 \\
$69^{\circ}$ & 1.611 & 1.619 & -0.008 & 0.50 \\
$73^{\circ}$ & 1.422 & 1.432 & -0.010 & 0.70 \\
$77^{\circ}$ & 1.188 & 1.201 & -0.013 & 1.09 \\
$81^{\circ}$ & 0.000 & 0.000 & 0.000 & 0.00 \\
\hline
\end{tabular}

relative error is $0.59 \%$, which indicates that the error is relatively small. Within the allowable range, the fitting value is very close to the measured value, and the curve fitting is good.

From equation (25), the blasting volume of $67^{\circ}$ wedge cutting model experiment can be calculated as the optimal value, with a blasting volume value of $8.390 \times 10^{-3} \mathrm{~m}^{3}$, as shown in Figure 9. 


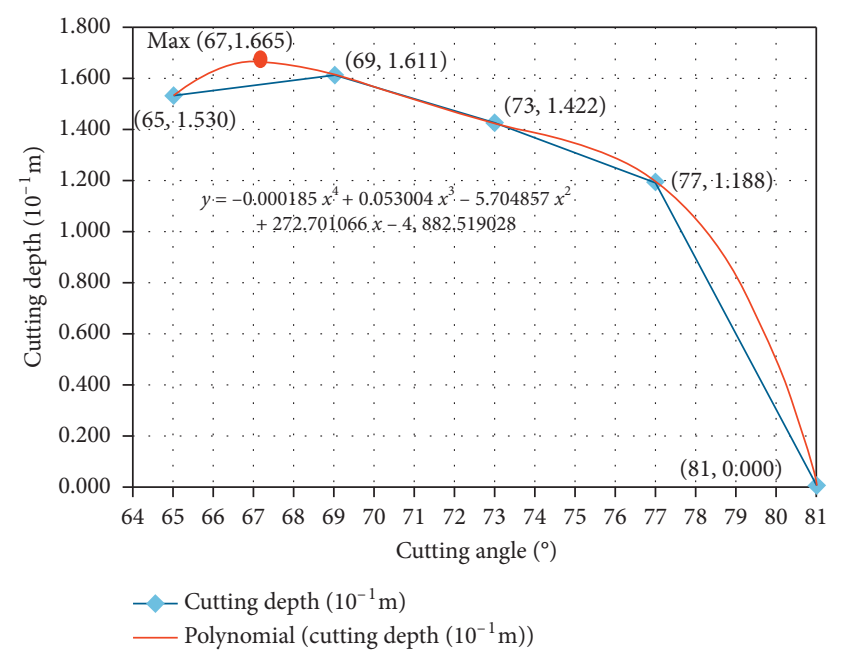

FIGURE 7: Fitting curves of wedge cutting models with different angles and cutting depth.

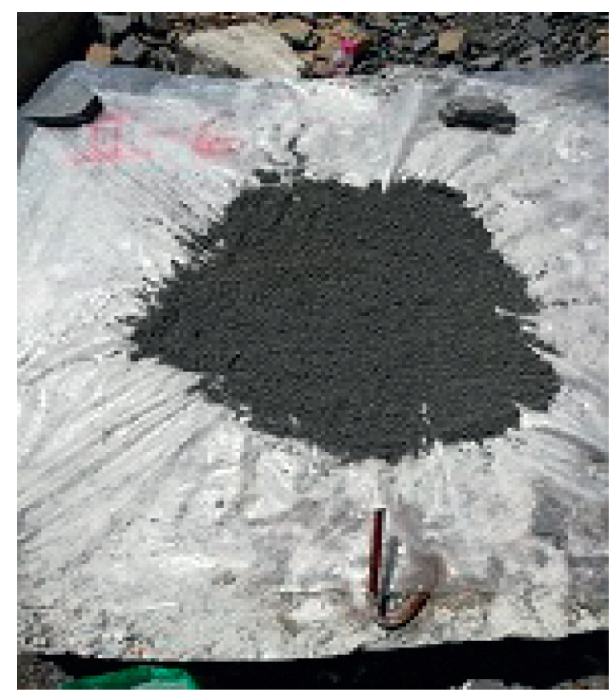

FIgURe 8: Blasting volume measurement.

TABLE 6: Error analysis table of blasting volume fitting formula.

\begin{tabular}{lcccc}
\hline $\begin{array}{l}\text { Cutting } \\
\text { angle }\end{array}$ & $\begin{array}{c}V \text { (measured } \\
\text { value) }\left(10^{-3} \mathrm{~m}^{3}\right)\end{array}$ & $\begin{array}{c}V^{*} \text { (fitting } \\
\text { value) } \\
\left(10^{-3} \mathrm{~m}^{3}\right)\end{array}$ & $V-V^{*}$ & $\begin{array}{c}\text { Relative } \\
\text { error }(\%)\end{array}$ \\
\hline $65^{\circ}$ & 7.410 & 7.390 & 0.020 & 0.27 \\
$69^{\circ}$ & 8.215 & 8.190 & 0.025 & 0.31 \\
$73^{\circ}$ & 7.165 & 7.135 & 0.030 & 0.42 \\
$77^{\circ}$ & 5.920 & 5.885 & 0.035 & 0.59 \\
$81^{\circ}$ & 0.000 & 0.000 & 0.000 & 0.00 \\
\hline
\end{tabular}

\subsection{Statistical Analysis of Model Cutting Blasting Fragmentation}

4.3.1. Histogram of Blasting Fragmentation Distribution. When the test is blasted, the blasting fragmentation of the plough cut model with different cutting angles is analyzed. Then use the ZBSX-92A shock-type dual-purpose vibrating pendulum screen machine produced by Zhejiang Shangyu

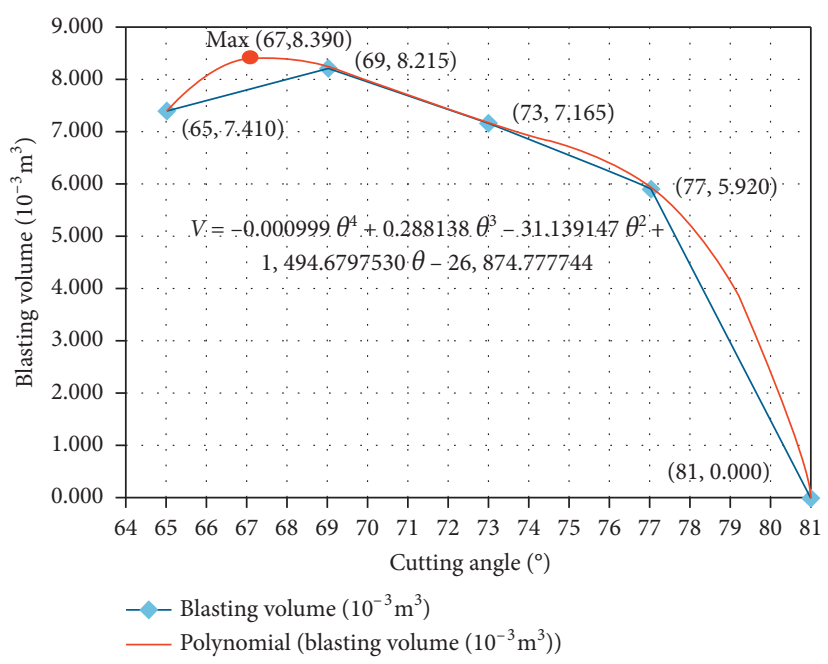

FIGURE 9: Fitting curves of wedge cutting models with different angles and blasting volume.

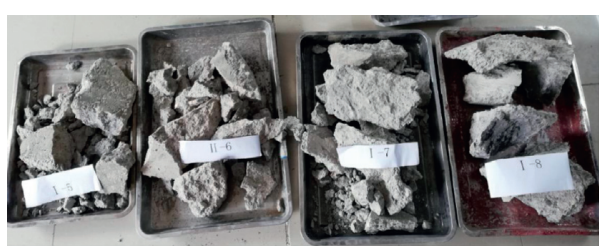

FIGURE 10: Blasting fragments.

Xinguang Instrument and Equipment Factory and the national new standard square hole stone screen machine to weigh and separate the different particle size and block size by electronic scale, which is shown in Figures 10-12.

According to the distribution of blasting fragmentation, the particle size is divided into 7 grades. The block size distribution of the blasted plough cut with five different cutting angles will be shown in Table 7 .

According to the statistical Table 7 of the screening of blasting fragmentation, the histogram of blasting fragmentation distribution of plough cut model test with five different angle is obtained, as shown in Figure 13.

Due to the large angle of $81^{\circ}$ wedge cutting, the cutting was not successful. According to the analysis of Figure 13, the other four plough cutting models with different angles all contain blasting blocks in models with ranges less than $9.5 \mathrm{~mm}$. Among these, the mass percentage of the plough cutting model with an angle of $65^{\circ}$ is the largest, while the mass percentage with an angle of $69^{\circ}$ is the smallest. In the range of $9.5 \mathrm{~mm}-19 \mathrm{~mm}$, four kinds of plough cutting models with different angles all contain blasting blocks. Among these, the mass percentage of the plough cutting model with an angle of $77^{\circ}$ is the largest, while the mass percentage with an angle of $73^{\circ}$ is the smallest. In the range of $19 \mathrm{~mm}-31.5 \mathrm{~mm}$, four kinds of plough cutting models with different angles all contain blasting blocks. Among these, the mass percentage of the plough cutting model with an angle of $65^{\circ}$ is the largest, while the mass percentage with an angle of $77^{\circ}$ is the smallest. In the range of $31.5 \mathrm{~mm}-53 \mathrm{~mm}$, four 


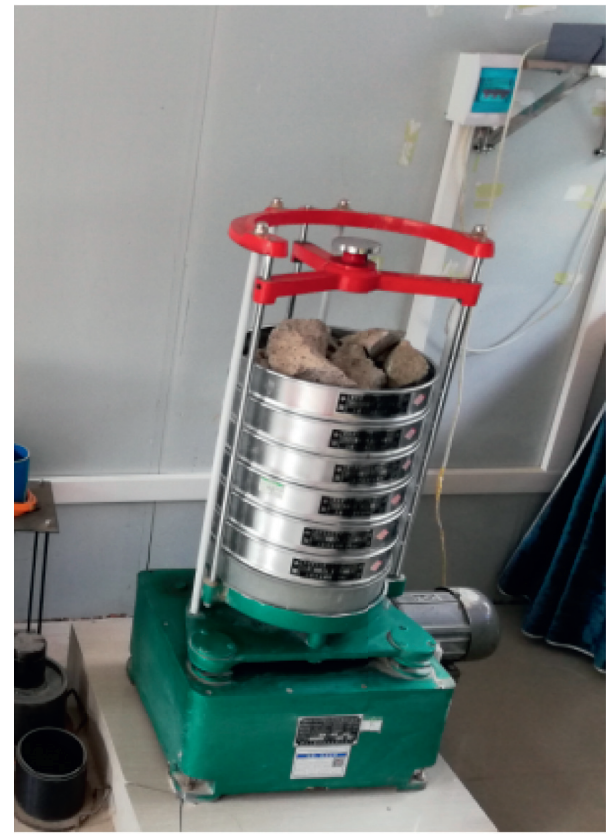

FIGURE 11: ZBSX-92A shock-type dual-purpose pendulum screening machine.

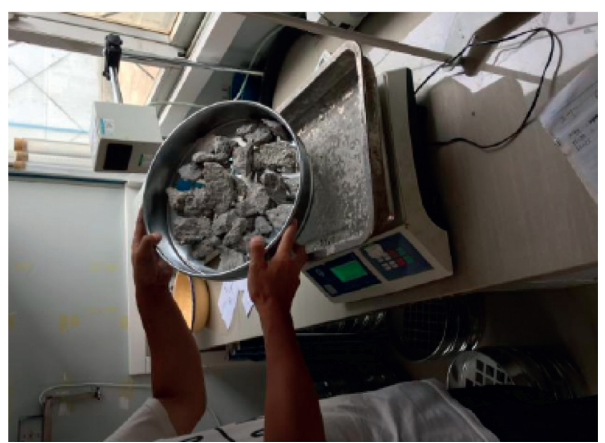

FIGURE 12: Fragments weighing.

TABLE 7: Statistical table of blasting block degree of wedge-shaped notch model test.

\begin{tabular}{|c|c|c|c|c|c|c|c|c|c|}
\hline Cutting mode & Specimen no. & Fragment grade $(\mathrm{mm})$ & $<9.5$ & $9.5 \sim 19$ & $19 \sim 31.5$ & $31.5 \sim 53$ & $53 \sim 75$ & $75 \sim 90$ & $>90$ \\
\hline \multirow{4}{*}{$65^{\circ}$ wedge cutting } & \multirow{4}{*}{ I-5, II-5 } & Mass $(\mathrm{kg})$ & 0.572 & 1.253 & 2.759 & 3.126 & 4.512 & 0.861 & 2.522 \\
\hline & & Cumulative mass $(\mathrm{kg})$ & 0.572 & 1.825 & 4.584 & 7.710 & 12.222 & 13.083 & 15.605 \\
\hline & & Mass percentage (\%) & 3.666 & 8.029 & 17.680 & 20.032 & 28.914 & 5.517 & 16.162 \\
\hline & & Cumulative mass percentage (\%) & 3.666 & 11.695 & 29.375 & 49.407 & 78.321 & 83.838 & 100.000 \\
\hline \multirow{4}{*}{$69^{\circ}$ wedge cutting } & \multirow{4}{*}{ I-6, II-6 } & Mass $(\mathrm{kg})$ & 0.249 & 1.659 & 2.552 & 3.442 & 4.280 & 1.125 & 2.891 \\
\hline & & Cumulative mass $(\mathrm{kg})$ & 0.249 & 1.908 & 4.460 & 7.902 & 12.182 & 13.307 & 16.198 \\
\hline & & Mass percentage (\%) & 1.537 & 10.242 & 15.755 & 21.250 & 26.423 & 6.945 & 17.848 \\
\hline & & Cumulative mass percentage (\%) & 1.537 & 11.779 & 27.534 & 48.784 & 75.207 & 82.152 & 100.000 \\
\hline \multirow{4}{*}{$73^{\circ}$ wedge cutting } & \multirow{4}{*}{ I-7, II-7 } & Mass $(\mathrm{kg})$ & 0.407 & 1.056 & 1.912 & 2.861 & 4.615 & 1.236 & 3.119 \\
\hline & & Cumulative mass $(\mathrm{kg})$ & 0.407 & 1.463 & 3.375 & 6.236 & 10.851 & 12.087 & 15.206 \\
\hline & & Mass percentage (\%) & 2.677 & 6.944 & 12.574 & 18.815 & 30.350 & 8.128 & 20.512 \\
\hline & & Cumulative mass percentage (\%) & 2.677 & 9.621 & 22.195 & 41.010 & 71.360 & 79.488 & 100.000 \\
\hline \multirow{4}{*}{$77^{\circ}$ wedge cutting } & \multirow{4}{*}{ I-8, II-8 } & Mass $(\mathrm{kg})$ & 0.223 & 1.592 & 1.326 & 1.513 & 1.876 & 2.131 & 5.816 \\
\hline & & Cumulative mass $(\mathrm{kg})$ & 0.223 & 1.815 & 3.141 & 4.654 & 6.530 & 8.661 & 14.477 \\
\hline & & Mass percentage (\%) & 1.540 & 10.997 & 9.159 & 10.451 & 12.958 & 14.720 & 40.175 \\
\hline & & Cumulative mass percentage (\%) & 1.540 & 12.537 & 21.696 & 32.147 & 45.105 & 59.825 & 100.000 \\
\hline \multirow{4}{*}{$81^{\circ}$ wedge cutting } & \multirow{4}{*}{ I-9, II-9 } & Mass $(\mathrm{kg})$ & 0.000 & 0.000 & 0.000 & 0.000 & 0.000 & 0.000 & 0.000 \\
\hline & & Cumulative mass $(\mathrm{kg})$ & 0.000 & 0.000 & 0.000 & 0.000 & 0.000 & 0.000 & 0.000 \\
\hline & & Mass percentage (\%) & 0.000 & 0.000 & 0.000 & 0.000 & 0.000 & 0.000 & 0.000 \\
\hline & & Cumulative mass percentage (\%) & 0.000 & 0.000 & 0.000 & 0.000 & 0.000 & 0.000 & 0.000 \\
\hline
\end{tabular}




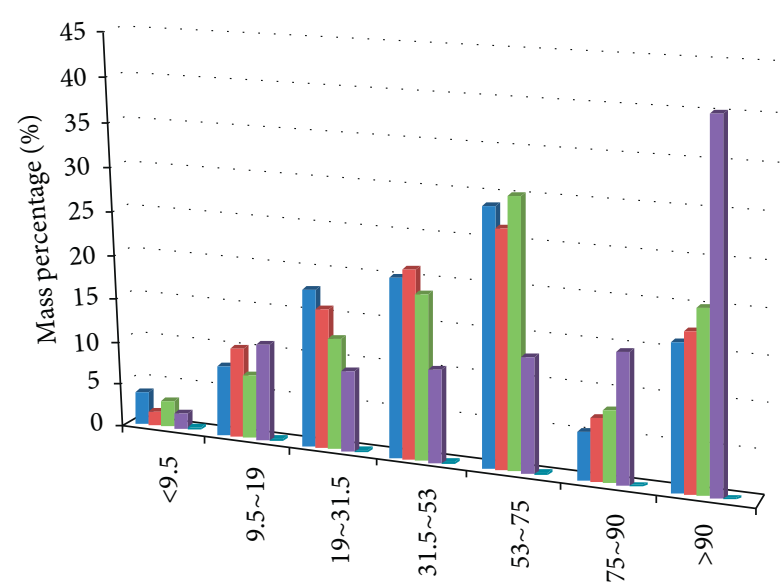

The sizing of blasting fragments $(\mathrm{mm})$

$$
\begin{aligned}
& \text { - } 65^{\circ} \text { wedge cutting } \quad-77^{\circ} \text { wedge cutting } \\
& -69^{\circ} \text { wedge cutting } \quad-81^{\circ} \text { wedge cutting } \\
& -73^{\circ} \text { wedge cutting }
\end{aligned}
$$

FIGURE 13: Histogram of blasting fragments of wedge-shaped recessed model at different angles.

kinds of plough cutting models with different angles all contain blasting blocks. Among these, the mass percentage of the plough cutting model with an angle of $69^{\circ}$ is the largest, while the mass percentage with an angle of $77^{\circ}$ is the smallest. In the range of $53 \mathrm{~mm}-75 \mathrm{~mm}$, four kinds of plough cutting models with different angles all contain blasting blocks. Among these, the mass percentage of the plough cutting model with an angle of $73^{\circ}$ is the largest, while the mass percentage with an angle of $77^{\circ}$ is the smallest. In the range of more than $75 \mathrm{~mm}$, four kinds of plough cutting models with different angles all contain blasting blocks. Among these, the mass percentage of the plough cutting model with an angle of $77^{\circ}$ is the largest, while the mass percentage with an angle of $65^{\circ}$ is the smallest.

4.3.2. The Relationship between the Cumulative Mass Percentage of Blasting Fragmentation and its Particle Size. According to the statistical Table 7 of the screening of blasting fragmentation, the relation curve between the cumulative mass percentage of each block size and the particle size of blocks is obtained, as shown in Figures 14-17.

From Figure 14, it can be concluded that the relationship between the cumulative mass percentage of plough cut blasting with an angle of $65^{\circ}$ is as follows:

$$
\begin{aligned}
y(x)= & 0.000002 x^{4}-0.000541 x^{3}+0.038735 x^{2} \\
& +0.104832 x-0.133720 .
\end{aligned}
$$

From equation (26), it can be calculated that the blasting fragmentation of plough cut with an angle of $65^{\circ}$ is $49.72 \mathrm{~mm}$. If the blasting fragmentation is larger than $55 \mathrm{~mm}$, the block rate is

$$
\eta=1-y(55)
$$

calculated as $\eta=1-y(55)=1-51.10 \%=48.90 \%$.

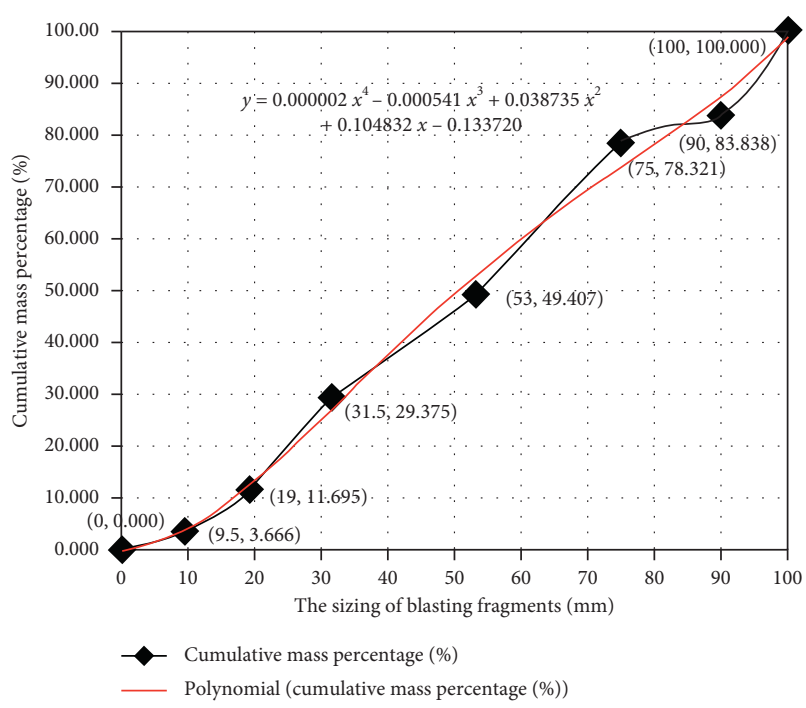

FIGURE 14: Relationship between cumulative mass percentage of blasting fragments and fragment size particle diameter of $65^{\circ}$ wedge cutting.

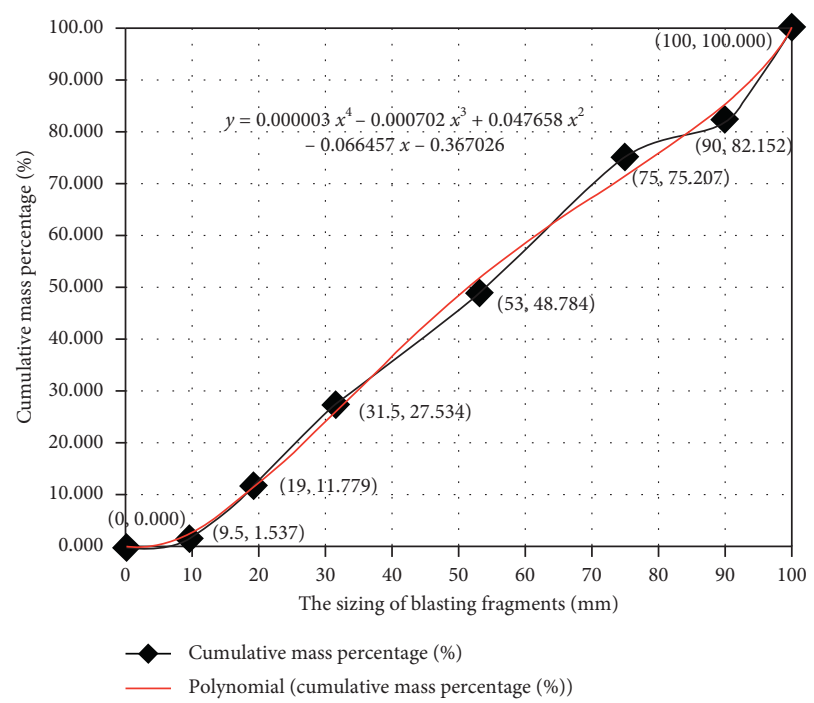

FIGURE 15: Relationship between cumulative mass percentage of blasting fragments and fragment size particle diameter of $69^{\circ}$ wedge cutting.

From Figure 15, it can be concluded that the relationship between the cumulative mass percentage of plough cut blasting with an angle of $69^{\circ}$ is as follows:

$$
\begin{aligned}
y(x)= & 0.000003 x^{4}-0.000702 x^{3}+0.047658 x^{2} \\
& -0.066457 x-0.367026 .
\end{aligned}
$$

From equation (28), it can be calculated that the blasting fragmentation of plough cut with an angle of $69^{\circ}$ is $54.02 \mathrm{~mm}$. The block rate is

$$
\eta=1-y(55)=1-50.80 \%=49.20 \% .
$$

From Figure 16, it can be concluded that the relationship between the cumulative mass percentage of plough cut blasting with an angle of $73^{\circ}$ is as follows: 


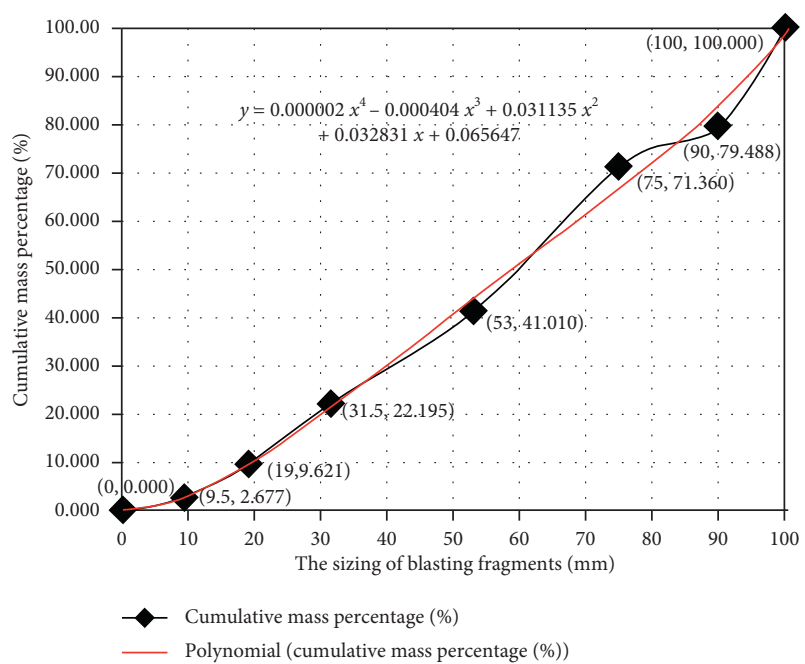

FIGURE 16: Relationship between cumulative mass percentage of blasting fragments and fragment size particle diameter of $73^{\circ}$ wedge cutting.

$$
\begin{aligned}
y(x)= & 0.000002 x^{4}-0.000404 x^{3}+0.031135 x^{2} \\
& +0.032831 x+0.065647
\end{aligned}
$$

From equation (30), it can be calculated that the blasting fragmentation of plough cut with an angle of $73^{\circ}$ is $57.54 \mathrm{~mm}$. The block rate is

$$
\eta=1-y(55)=1-47.14 \%=52.86 \% \text {. }
$$

From Figure 17, it can be concluded that the relationship between the cumulative mass percentage of plough cut blasting with an angle of $77^{\circ}$ is as follows:

$$
\begin{aligned}
y(x)= & 0.000007 x^{4}-0.001158 x^{3}+0.056108 x^{2} \\
& -0.131097 x-0.149017
\end{aligned}
$$

From equation (32), it can be calculated that the blasting fragmentation of plough cut with an angle of $65^{\circ}$ is $86.08 \mathrm{~mm}$. The block rate is

$$
\eta=1-y(55)=1-33.76 \%=66.24 \% \text {. }
$$

The average blasting fragmentation of $81^{\circ}$ wedge cutting is $\infty$ and the bulk rate is $100 \%$ because the inclination of the hole of $81^{\circ}$ wedge cutting model is large and the cutting is not successful in blasting.

From the above calculation, the statistical table of the blasting fragmentation index of wedge cutting with different cutting angles can be obtained, as shown in Table 4 . According to the calculation, the trend of the plotted blasting fragment and block rate with the cutting angle is shown in Figures 18 and 19.

For the sake of intuition, the blasting fragment data in Table 4 can be obtained by fitting equation (23).

$$
D=1762.211188-50.924625 \theta+0.378438 \theta^{2},
$$

As can be seen from Table 8 , the maximum absolute error of blasting fragment is $-3.87 \mathrm{~mm}$, and the maximum relative error is $7.15 \%$, which indicates that the error is

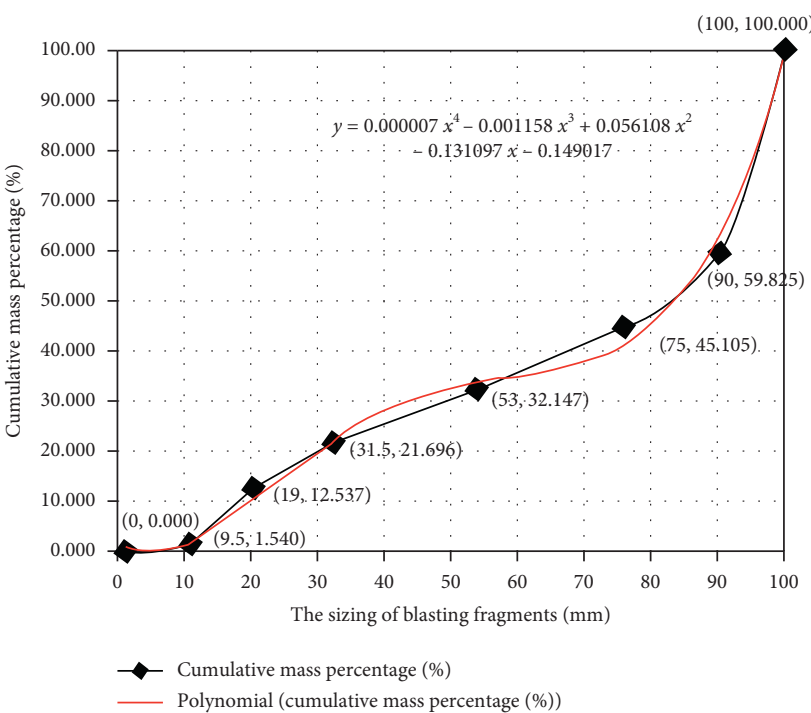

Figure 17: Relationship between cumulative mass percentage of blasting fragments and fragment size particle diameter of $77^{\circ}$ wedge cutting.

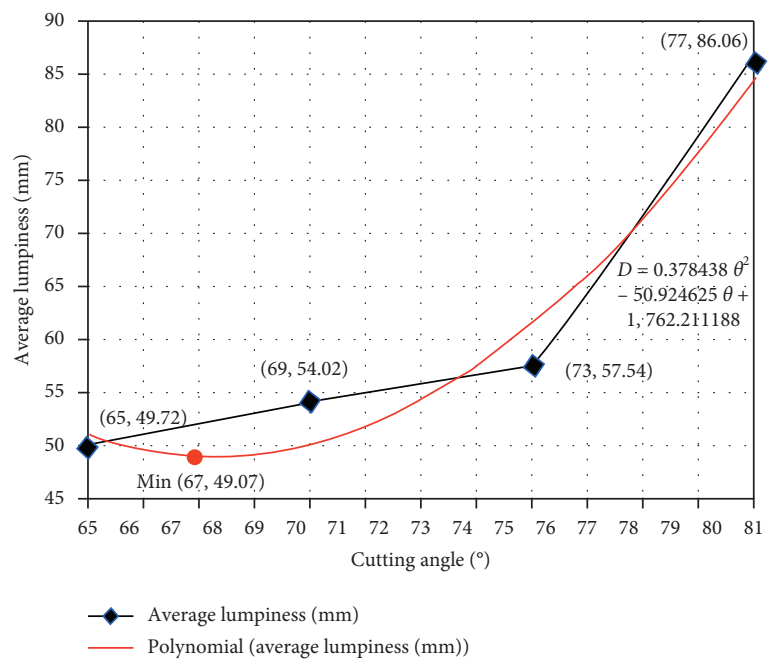

FIgURE 18: Fitting curves of wedge cutting model and blasting fragments at different angles.

relatively small. Within the allowable range, the fitting value is very close to the measured value, and the curve fitting is good.

From equation (34), the blasting fragment of $67^{\circ}$ wedge cutting model experiment can be calculated as the optimal value, with a blasting fragment value of $49.07 \mathrm{~mm}$, as shown in Figure 18.

Carrying out polynomial regression fitting on the relationship between the wedge cutting model at different angles and the block rate trend in Figure 19, the relationship can be obtained as

$$
\begin{aligned}
y(x)= & 0.002212 \theta^{4}-0.575658 \theta^{3}+56.233179 \theta^{2} \\
& -2443.763930 \theta+39914.165020 .
\end{aligned}
$$




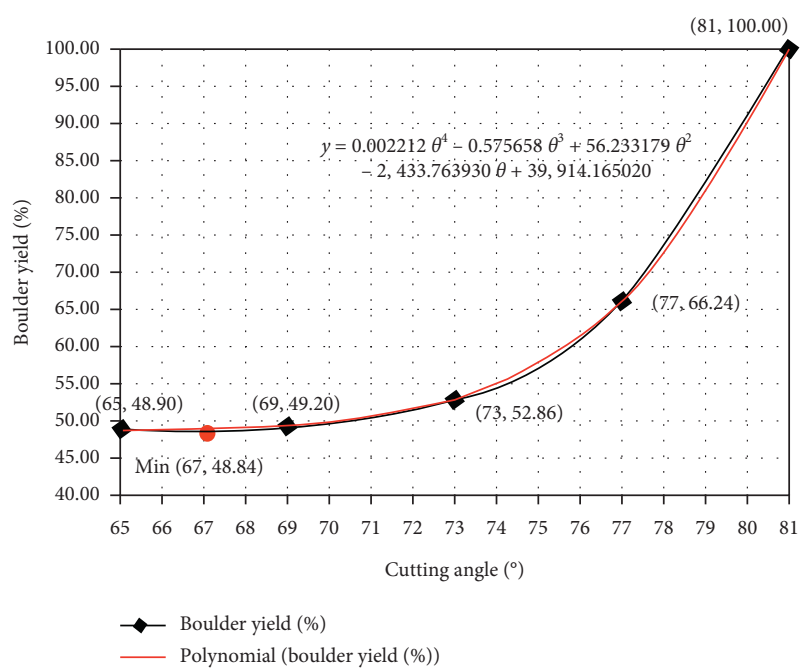

FIGURE 19: The trend of wedge cutting model and the bulk rate at different angles.

TABLE 8: Error analysis table of blasting fragment fitting formula.

\begin{tabular}{lcccc}
\hline $\begin{array}{l}\text { Cutting } \\
\text { angle }\end{array}$ & $\begin{array}{c}D \text { (measured } \\
\text { value) }\left(10^{-3} \mathrm{~m}^{3}\right)\end{array}$ & $\begin{array}{c}D^{*} \text { (fitting } \\
\text { value) } \\
\left(10^{-3} \mathrm{~m}^{3}\right)\end{array}$ & $D-D^{*}$ & $\begin{array}{c}\text { Relative } \\
\text { error }(\%)\end{array}$ \\
\hline $65^{\circ}$ & 49.72 & 51.01 & -1.29 & 2.59 \\
$69^{\circ}$ & 54.02 & 50.16 & 3.86 & 7.15 \\
$73^{\circ}$ & 57.54 & 61.41 & -3.87 & 6.73 \\
$77^{\circ}$ & 86.06 & 84.77 & 1.29 & 1.50 \\
$81^{\circ}$ & $\infty$ & $\infty$ & 0.00 & 0.00 \\
\hline
\end{tabular}

From equation (35), the block rate of $67^{\circ}$ wedge cutting model experiment can be calculated as the optimal value, with a block rate value of $48.84 \%$.

In conclusion, when the explosive consumption of five wedge cutting model tests with different cutting angles is the same, the wedge cutting blasting effect with $67^{\circ}$ cutting angle is the best in terms of cutting depth, blasting hole utilization ratio, blasting volume, blasting fragment, blasting block rate, and other main indexes after blasting.

\section{Blasting Vibration Test}

5.1. Design of Blasting Vibration Test. TC4850N wireless network vibration meter produced by Chengdu Zhengzhou Measurement and Control Co.Ltd. was used to test the blasting vibration of each cutting model. The vibration meter is equipped with an integrated threedimensional sensor, which is easy to install and simple to connect. It is particularly suitable for the unattended test site and long-term monitoring of complex environment. It can transmit data through $3 \mathrm{G}$ communication and $\mathrm{Wi}$ Fi function and use special software for data processing and analysis. This description is as followed: four channels are available in parallel; the sampling rate is 100 sps-100 ksps, and multiple levels can be adjusted; the resolution of $A / D$ level is 16 bits; the frequency response

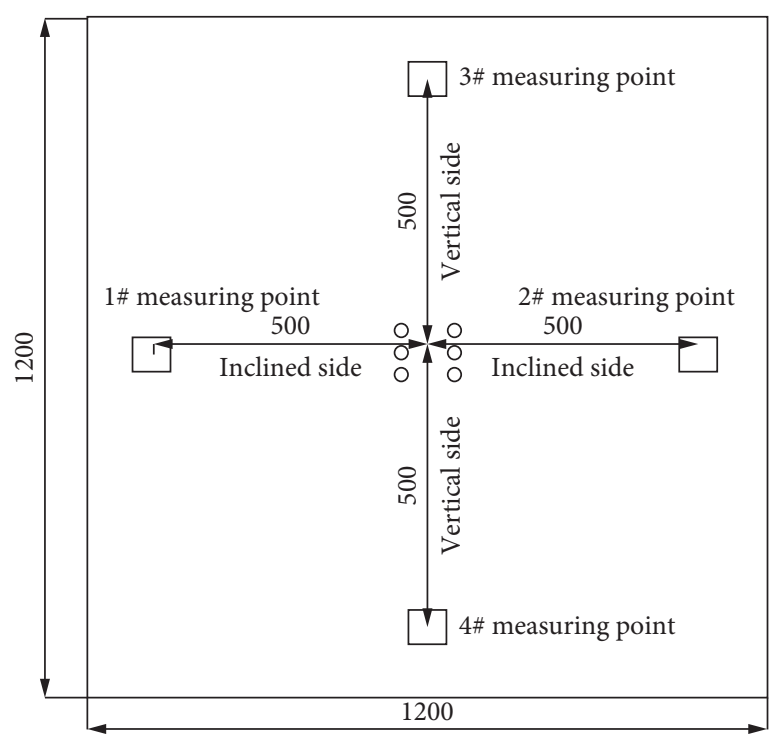

FIgURE 20: Schematic diagram of measuring points of wedgeshaped notch blasting vibration at different angles (unit: $\mathrm{mm}$ ).

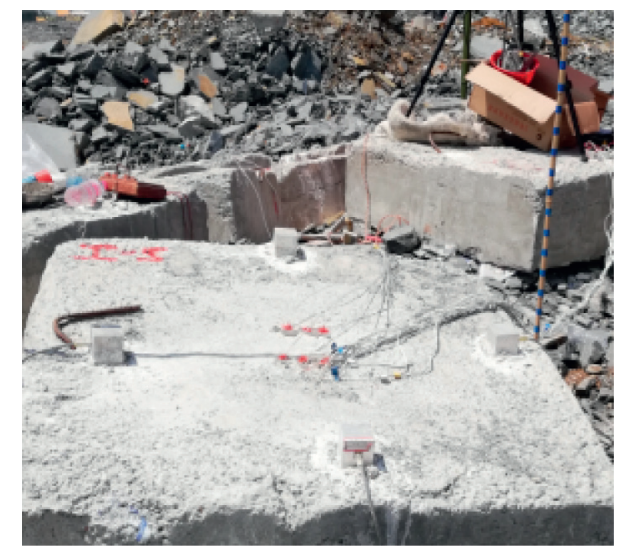

Figure 21: Actual layout of blasting vibration sensors.

range is $0-10 \mathrm{kHz}$; single record, automatic repeat record, and continuous record are available; the recording time is adjustable from 1 to $5000 \mathrm{~s}$; it can be triggered internally, externally, synchronously, and regularly; the measuring range is plus or minus $10 \mathrm{~V}$; the storage capacity is $256 \mathrm{MB}$.

In order to compare the blasting vibration effect in different directions of the plough cutting, both sides of the slope of it are defined as an inclined side, and the other two ends are vertical side. Speed sensors are used in four directions of each group of test blastholes, and $X$-axis of all sensors is facing the explosion source, $500 \mathrm{~mm}$ away from the central line of blastholes. The layout of measuring points is shown in Figures 20 and 21.

\subsection{Blasting Vibration Test Results and Analysis}

5.2.1. Vibration Test Results. See Table 9 for the test results of peak vibration speed and the main vibration frequency of 
TABLE 9: Test results of blasting peak vibration velocity.

\begin{tabular}{|c|c|c|c|c|c|c|c|c|c|c|}
\hline \multirow[b]{2}{*}{$\begin{array}{l}\text { Cutting } \\
\text { mode }\end{array}$} & \multirow[b]{2}{*}{ Location } & \multirow[b]{2}{*}{$\begin{array}{l}\text { Measuring } \\
\text { point } \\
\text { number }\end{array}$} & \multicolumn{3}{|c|}{ Peak vibration velocity $\left(\mathrm{cm} \cdot \mathrm{s}^{-1}\right)$} & \multirow[b]{2}{*}{$\begin{array}{c}\text { Resultant } \\
\text { velocity } \\
\left(\mathrm{cm} \cdot \mathrm{s}^{-1}\right)\end{array}$} & \multirow{2}{*}{$\begin{array}{l}\text { Average } \\
\text { resultant } \\
\text { velocity } \\
\left(\mathrm{cm} \cdot \mathrm{s}^{-1}\right)\end{array}$} & \multicolumn{3}{|c|}{ Main frequency $(\mathrm{Hz})$} \\
\hline & & & $\begin{array}{c}\text { Radial } \\
\text { direction }\end{array}$ & $\begin{array}{l}\text { Tangential } \\
\text { direction }\end{array}$ & $\begin{array}{c}\text { Vertical } \\
\text { direction }\end{array}$ & & & $\begin{array}{c}\text { Radial } \\
\text { direction }\end{array}$ & $\begin{array}{c}\text { Tangential } \\
\text { direction }\end{array}$ & $\begin{array}{l}\text { Vertical } \\
\text { direction }\end{array}$ \\
\hline \multirow{4}{*}{$\begin{array}{l}65^{\circ} \\
\text { wedge } \\
\text { cutting }\end{array}$} & Inclined & $1^{\#}$ & 10.06 & 7.76 & 11.82 & 18.59 & \multirow{2}{*}{20.42} & 7.5 & 20.2 & 25.9 \\
\hline & side & $2^{\#}$ & 10.71 & 10.37 & 12.13 & 22.25 & & 5.8 & 12.3 & 39.1 \\
\hline & Vertical & $3^{\#}$ & 18.15 & 7.91 & 15.68 & 27.05 & \multirow[b]{2}{*}{25.21} & 17.2 & 19.2 & 32.3 \\
\hline & side & $4^{\#}$ & 13.22 & 6.17 & 16.47 & 23.37 & & 16.3 & 14.0 & 38.6 \\
\hline \multirow{4}{*}{$\begin{array}{l}69^{\circ} \\
\text { wedge } \\
\text { cutting }\end{array}$} & Inclined & $1^{\#}$ & 13.13 & 7.98 & 15.11 & 21.89 & \multirow{2}{*}{23.11} & 11.4 & 18.5 & 66.9 \\
\hline & side & $2^{\#}$ & 11.62 & 13.57 & 18.85 & 24.32 & & 37.8 & 16.9 & 90.1 \\
\hline & Vertical & $3^{\#}$ & 17.93 & 10.29 & 21.26 & 29.41 & \multirow{2}{*}{30.23} & 8.2 & 20.8 & 78.2 \\
\hline & side & $4^{\#}$ & 22.74 & 22.52 & 20.30 & 31.04 & & 55.6 & 33.3 & 66.7 \\
\hline \multirow{4}{*}{$\begin{array}{l}73^{\circ} \\
\text { wedge } \\
\text { cutting }\end{array}$} & Inclined & $1^{\#}$ & 12.93 & 16.76 & 11.55 & 24.98 & \multirow{2}{*}{27.27} & 9.5 & 8.3 & 63.3 \\
\hline & side & $2^{\#}$ & 14.68 & 18.12 & 20.58 & 29.55 & & 25.8 & 9.3 & 82.9 \\
\hline & Vertical & $3^{\#}$ & 23.91 & 25.43 & 22.60 & 32.46 & \multirow{2}{*}{33.06} & 18.6 & 26.2 & 110.2 \\
\hline & side & $4^{\#}$ & 22.20 & 10.01 & 24.93 & 33.66 & & 20.2 & 75.8 & 125.0 \\
\hline \multirow{4}{*}{$\begin{array}{l}77^{\circ} \\
\text { wedge } \\
\text { cutting }\end{array}$} & Inclined & $1^{\#}$ & 16.15 & 19.38 & 21.12 & 33.12 & \multirow{2}{*}{34.92} & 53.8 & 63.7 & 16.6 \\
\hline & side & $2^{\#}$ & 15.56 & 18.93 & 20.78 & 36.72 & & 90.5 & 58.5 & 106.0 \\
\hline & Vertical & $3^{\#}$ & 23.30 & 24.83 & 27.39 & 44.17 & \multirow{2}{*}{43.36} & 125.0 & 76.9 & 30.3 \\
\hline & side & $4^{\#}$ & 25.17 & 26.23 & 21.55 & 42.55 & & 13.7 & 125.0 & 18.9 \\
\hline \multirow{4}{*}{$\begin{array}{l}81^{\circ} \\
\text { wedge } \\
\text { cutting }\end{array}$} & Inclined & $1^{\#}$ & 19.92 & 21.55 & 26.17 & 41.44 & \multirow{2}{*}{42.36} & 95.7 & 18.3 & 106.5 \\
\hline & side & $2^{\#}$ & 21.36 & 19.66 & 27.78 & 43.28 & & 110.5 & 110.5 & 110.5 \\
\hline & Vertical & $3^{\#}$ & 27.65 & 29.11 & 35.49 & 48.19 & \multirow{2}{*}{48.76} & 125.0 & 25.8 & 90.0 \\
\hline & side & $4^{\#}$ & 23.81 & 24.75 & 36.04 & 49.33 & & 113.6 & 125.0 & 113.6 \\
\hline
\end{tabular}

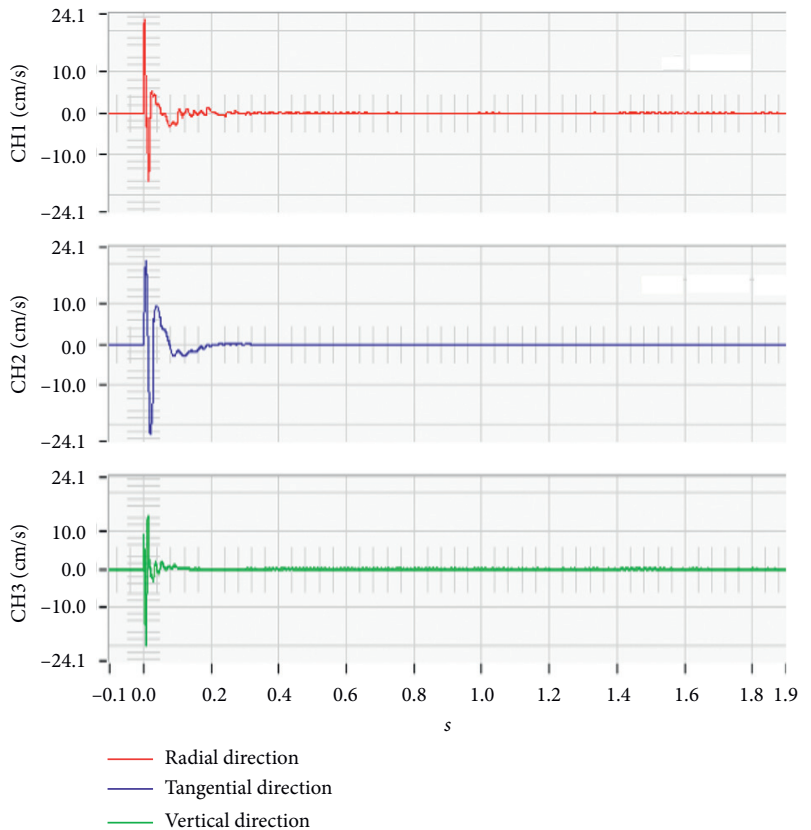

FIGURE 22: Model waveform of wedge cutting blasting.

blasting particle. The typical vibration waveform of the plough cut blasting is shown in Figure 22.

5.2.2. The Maximum Peak Vibration Velocity. At present, the peak vibration velocity is widely used as the evaluation standard of the blasting vibration hazard effect. It

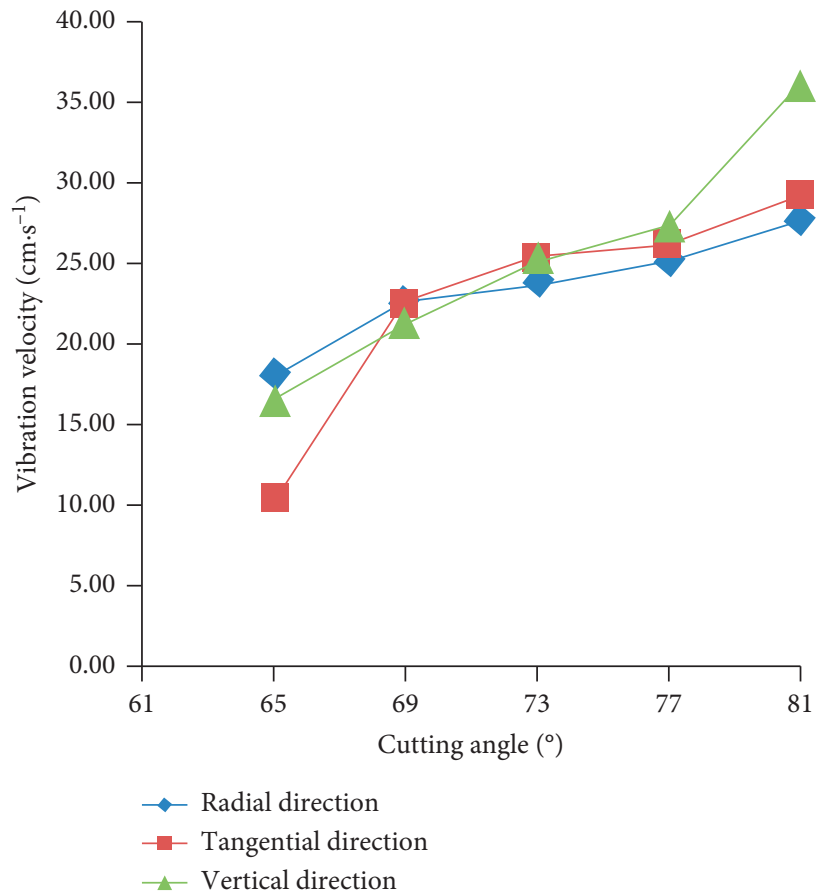

FIGURE 23: The curve of the maximum peak velocity with the change of cutting angle.

can be seen from Table 9 that the peak vibration velocity of horizontal radial and vertical blasting in each group of tests is larger, and the horizontal tangential direction is the smallest. The results show that the maximum peak vibration velocity is $81^{\circ}$ wedge cutting $>77^{\circ}$ wedge cutting 


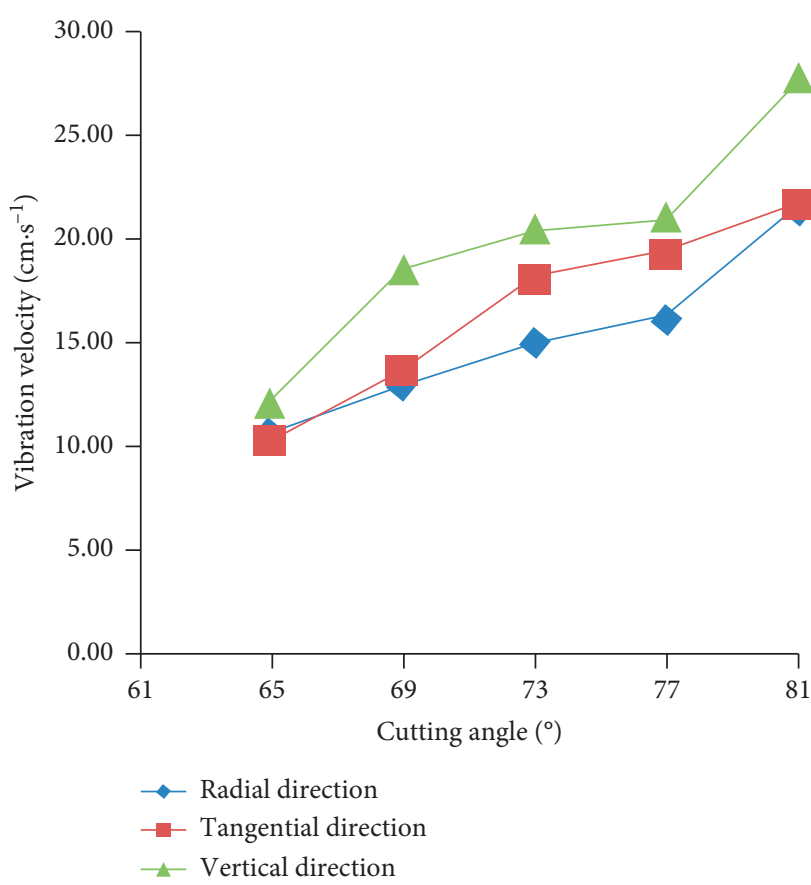

(a)

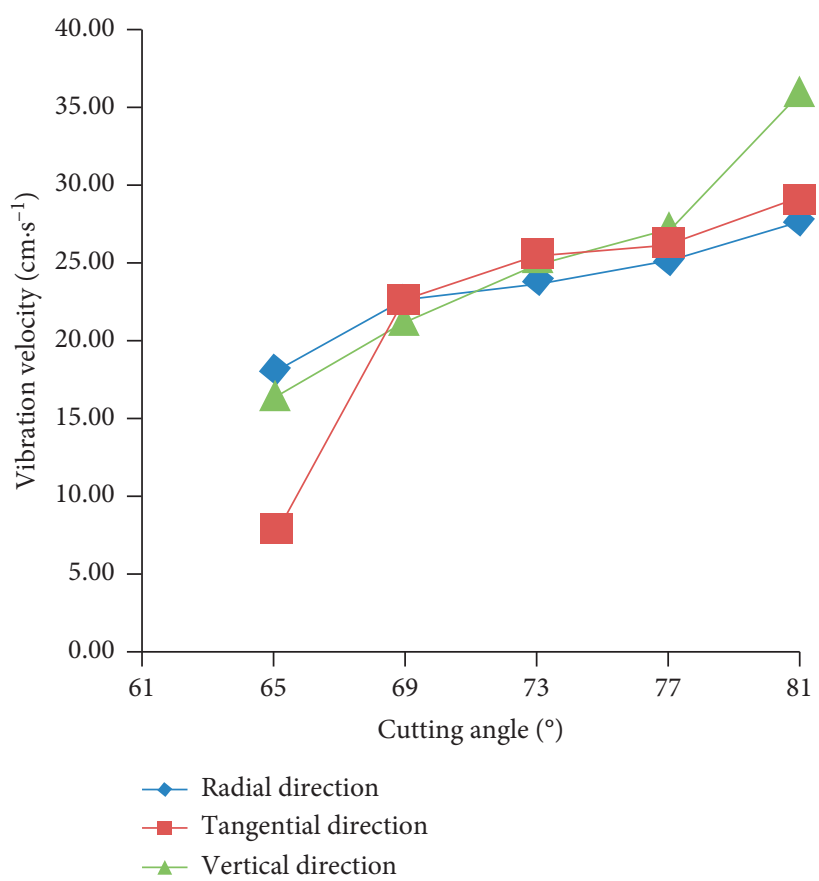

(b)

FIgURE 24: The curve of the (a) inclined and (b) vertical side maximum peak velocity with the change of cutting angle.

$>73^{\circ}$ wedge cutting $>69^{\circ}$ wedge cutting $>65^{\circ}$ wedge cutting. When the cutting angle is $81^{\circ}$, only through cracks are formed, and the cutting part is not thrown out. The energy generated by explosion is more converted into seismic wave, so the peak vibration velocity is the largest and the maximum peak velocity is $36.04 \mathrm{~cm} / \mathrm{s}$. When the cutting angle is $65^{\circ}$, the peak vibration velocity is the smallest and the maximum peak velocity is $18.15 \mathrm{~cm} / \mathrm{s}$.

It can be seen from Figure 23 that the maximum peak vibration speed in all directions increases with the increase of cutting angle, among which the change trend of tangential maximum vibration speed is the most obvious, and the change trend of radial and vertical maximum vibration speed is relatively stable.

It can be seen from Figure 24 that with the increase of cutting angle, the overall value of the maximum peak vibration velocity on the vertical side is greater than that on the inclined side; the trend of the maximum peak vibration velocity on the vertical side is the most obvious, and the trend of the maximum peak vibration velocity on the radial and tangential sides is more stable; the trend of the maximum peak vibration velocity on the vertical side is the most obvious, and the change of the maximum peak vibration velocity on the radial and vertical sides is the most obvious The trend is relatively stable.

5.2.3. Resultant Velocity. It can be seen from Table 9 that the average closing speed on the inclined side is smaller than that on the vertical side. When the cutting angle is $65^{\circ}$, the minimum average closing speed of the inclined side is $20.42 \mathrm{~cm} / \mathrm{s}$.

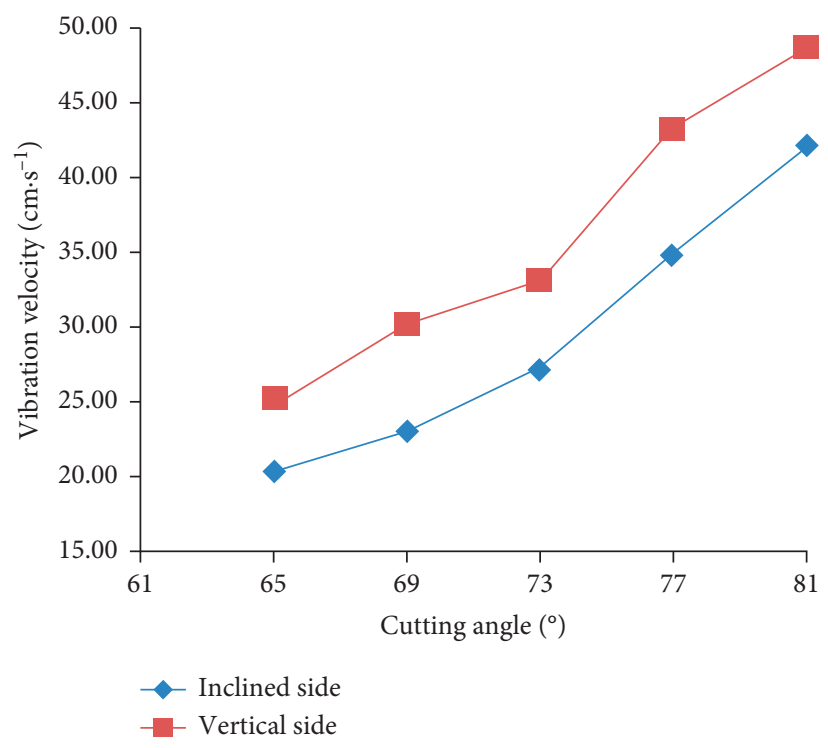

Figure 25: The curve of the inclined and vertical side average resultant velocity with the change of cutting angle.

It can be seen from Figure 25 that with the increase of cutting angle, the rising trend of average closing speed of the inclined side and vertical side is basically the same. When the cutting angle is $65^{\circ}$, the average closing velocity of the inclined side and the vertical side is the smallest.

Therefore, considering the cutting depth, blasting volume, blasting fragment, blasting vibration hazard, and construction difficulty, wedge cutting blasting with an angle of $65^{\circ} \sim 69^{\circ}$ is recommended in engineering practice. 


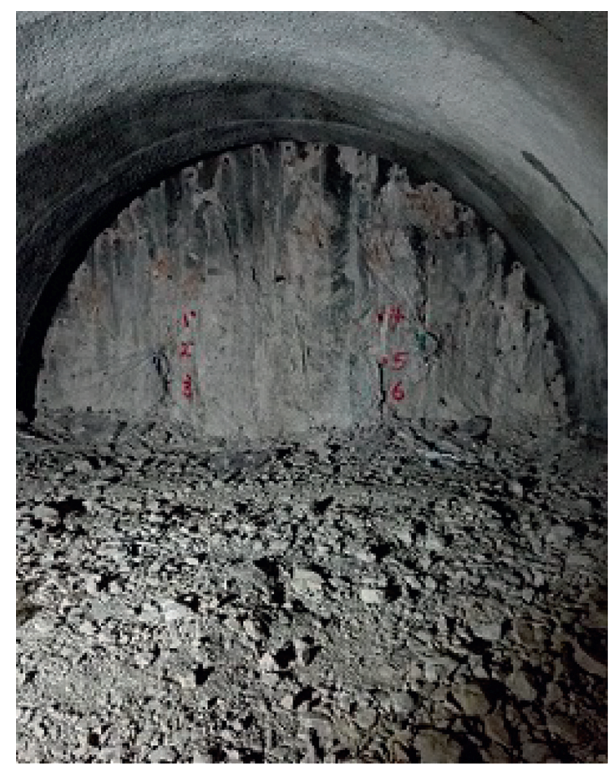

Figure 26: Layout of site blast holes.

And the blasting vibration intensity of the inclined side of wedge cutting is generally lower than that of the vertical side. In the excavation blasting of shallow buried tunnel, overlapping tunnel, and (super) small clear distance tunnel, it can effectively reduce the vibration hazard of excavation blasting by adjusting the layout direction of wedge cutting and making the inclined side face the key protection area.

\section{On-Site Tunneling Experiments with Different Cutting Angles}

In order to verify the theoretical analysis conclusion, several single-stage wedge cutting blasting experiments with five different cutting angles were carried out in Jugezhuang Tunnel of JSJJSG-9 bid section of the Beijing-Hebei section of the newlybuilt Beijing-Shenyang Passenger Dedicated Line, as shown in Figures 26 and 27. All cutting holes shall be enlarged 15 times according to the size in Figure 1 for manual drilling, and the cutting angle error shall be controlled within $1.5^{\circ}$. Under the condition that other blasting parameters remain unchanged, the effect of $65^{\circ}, 69^{\circ}, 73^{\circ}, 77^{\circ}$, and $81^{\circ}$ cutting angles on blasting excavation footage is discussed. The comparison of tunnel blasting footage when different cutting angles change is shown in Figure 28. The blasting footage takes the average value of multiple experiments.

As can be seen from Figure 28, with the increase of cutting angle, the excavation footage of tunnel blasting becomes shorter and shorter, especially when the cutting angle is above $73^{\circ}$, and the blasting footage is slower than that of excavation below $73^{\circ}$, which shows that the cutting angle has a great influence on the excavation footage. Considering that there is an error of $\pm 1.5^{\circ}$ in the field drilling angle and the cutting angle is in the range of $65^{\circ} \sim 69^{\circ}$, the footage of tunnel blasting excavation is the best, which is consistent with the theoretical analysis.

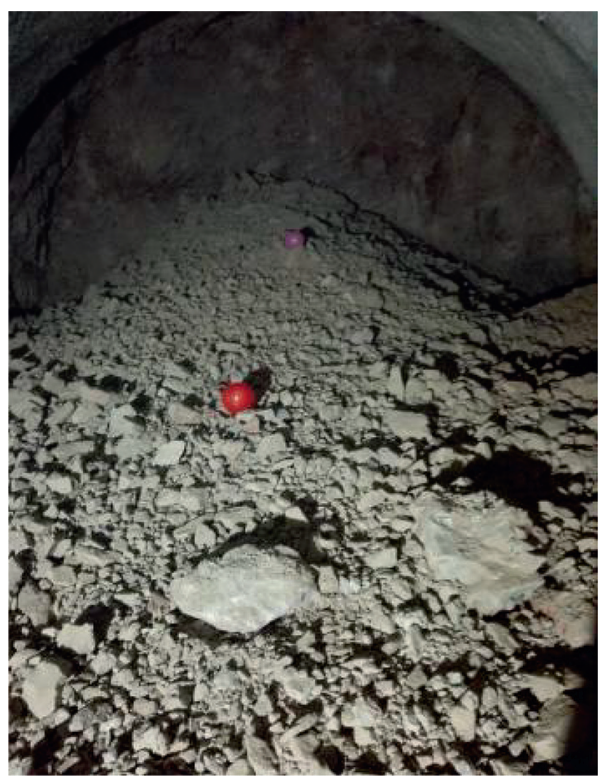

FIgURE 27: The picture of tunnel blasting effect.

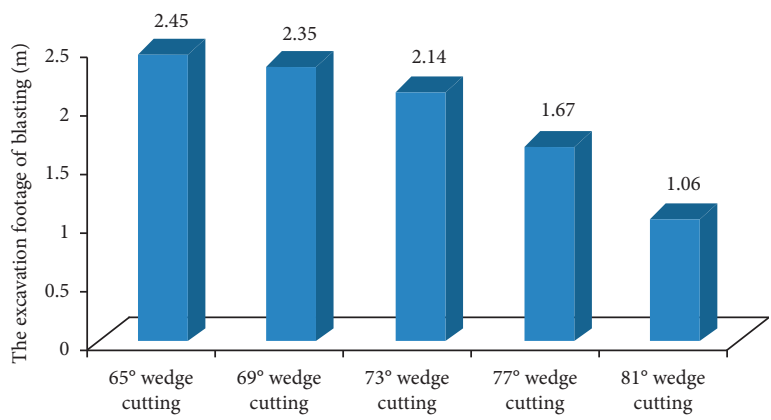

Figure 28: Comparison chart of tunneling footage when tunnel blasting cutting angle changes.

\section{Conclusions}

Based on the work presented, the following conclusions can be drawn regarding the experiment and the results thereof:

(1) Based on the similarity theory and the actual tunnel wedge cutting blasting, five kinds of tunnel section hole arrangement forms with different cutting angles were designed, concrete model specimens were made and blast holes were reserved, and wedge cutting blasting model experiments were carried out. Quantitative indexes such as cutting depth, blasting volume, blasting fragment, and blasting bulk rate of five kinds of wedge cutting ways with different angles were obtained.

(2) The relationship between cutting depth, blasting volume, blasting fragment, and cutting angle was studied and deduced by the dimensional analysis method, and the polynomial fitting of the relationship between cutting depth, blasting volume, blasting fragment, and cutting angle was carried out according to the experiment data, and the corresponding fitting equation was obtained. 
(3) Through the quantitative analysis and research on the experiment indexes of wedge cutting blasting, it was concluded that the experiment indexes of wedge cutting blasting depth, blasting volume, blasting fragment, and blasting bulk rate are better than those of wedge cutting blasting at $67^{\circ}$ cutting angle.

(4) The peak vibration velocity in radial and the vertical direction is larger than that in the tangential direction. The peak vibration velocity of wedge cutting with cutting angle of $65^{\circ}$ is the smallest. And the vibration intensity of the inclined side of wedge-shaped cutting is generally lower than that of the vertical side.

(5) Considering the cutting depth, blasting volume, blasting fragment, blasting vibration hazard, drilling error, tunneling construction cost, and other factors, the $65^{\circ} \sim 69^{\circ}$ wedge cutting blasting in engineering practice can improve the blasting tunneling rate and increase economic benefits.

\section{Data Availability}

The experimental data used to support the findings of this study are available from the corresponding author upon request.

\section{Conflicts of Interest}

The authors declare that they have no conflicts of interest.

\section{Acknowledgments}

This work was supported by the National Natural Science Foundation of China (Grants nos. 50704005 and 51664007), Scientific Research Fund Project of Yunnan Provincial Department of Education (Grant no. 2020J0051), and Fund from Kunming University of Science and Technology, (Grant no. KKSY201867017), which are greatly appreciated.

\section{References}

[1] W. B. Lu, Y. Luo, M. Chen, and D. Q. Shu, "An introduction to Chinese safety regulations for blasting vibration," Environmental Earth Sciences, vol. 67, no. 7, pp. 1951-1959, 2012.

[2] Z. Zhao, Y. Zhang, and H. Bao, "Tunnel blasting simulations by the discontinuous deformation analysis," International Journal of Computational Methods, vol. 8, no. 2, pp. 277-292, 2011.

[3] U. Langefors and B. Kihlstrom, Modern Technology of Rock Blasting, Metallurgical Industry Press, Beijing, China, 1983.

[4] V. Y. Shapiro, "Efficiency of cut configuration in driving tunnels with a set of deep blast holes," Soviet Mining Science, vol. 25, no. 4, pp. 379-386, 1989.

[5] M. Cardu and J. Seccatore, "Quantifying the difficulty of tunneling by drilling and blasting," Tunneling and Underground Space Technology, vol. 60, pp. 178-182, 2016.

[6] Z. X. Dong and S. R. Wang, "Optimization study of undermine method and undermine parameters," Explosion and Shock Waves, vol. 18, no. 4, pp. 381-386, 1998.

[7] Z. X. Dong, D. P. Li Dianping, Z. L. Li, Q. Z. Xie, and H. R. Liu, "Evaluation and analysis on the rationality of undermine patterns and parameters for tunneling," Chinese Journal of
Rock Mechanics and Engineering, vol. 22, no. 9, pp. 1478-1482, 2003.

[8] J. Dai and Y. Q. Yang, "Study on blasting parameters of triangular column straight holes," Explosion and Shock Waves, vol. 20, no. 4, pp. 364-368, 2000.

[9] D. Q. Zhang and H. L Tian, "Determination of reasonable grooving type for deep hole blasting in rock lane," Safety in Coal Mines, vol. 36, no. 5, pp. 30-32, 2005.

[10] C. B. Liu and H. B. Gao, "Multirow single directional cutting used in underground tunnel excavation," Mining Engineering, vol. 6, no. 4, pp. 44-45, 2008.

[11] Q. T. Pei and J. H. Chen, "Design of combination of smooth blasting and double-wedge cut for roadway excavation," Mining Research and Development, vol. 29, no. 1, pp. 75-77, 2009.

[12] W. M. Liang, Y. X. Wang, H. B. Chu, and X. L. Yang, "Study on effect of symmetry of wedge cutting hole angle on cut blasting," Metal Mine, vol. 42, no. 11, pp. 21-24, 2009.

[13] H. B. Chu, W. M. Liang, X. L. Yang, and Y. Q. Yu, "Experimental study on tunnel wedge cut blasting," Modern Tunneling Technology, vol. 47, no. 4, pp. 27-30, 2010.

[14] H. M. Xiong, G. H. Cheng, R. F. Liao, H. P. Lu, and J. Luo, "Influence factors analysis of wedge slotting blasting based on analytical hierarchy process," Engineering Blasting, vol. 17, no. 4, pp. 26-30, 2011.

[15] W. H. Yuan, Q. Y. Ma, and W. Huang, "Model experiment and analysis of wedge cutting millisecond blasting," Chinese Journal of Rock Mechanics and Engineering, vol. 31, no. 5, pp. 3352-3356, 2012.

[16] C. J. Pu, T. Liao, D. J. Xiao, J. Q. Wang, and R. Jiang, “Grey relational analysis of influence factors on rock tunnel wedge cut blasting," Industrial Minerals \& Processing, vol. 3, pp. 34-38, 2016.

[17] J. H. Hu, C. Yang, K. P. Zhou, B. R. Zhou, and S. G. Zhang, "Temporal-spatial evolution and application of blasting cavity of single wedge cutting," Journal of Central South University (Science and Technology), vol. 48, no. 12, pp. 3309-3315, 2017.

[18] Z. R. Zhang Zhaoranang and R. S. Yang, "Multi-step cutting technology and its application in rock roadways," Chinese Journal of Rock Mechanics and Engineering, vol. 38, no. 3, pp. 551-559, 2019.

[19] M. Gong, B. Wen, and H. Wang, "Influence of cut parameters on blasting effect in rock roadway of coal mine," Explosion and Shock Waves, vol. 35, no. 4, pp. 576-584, 2015.

[20] M. Gong, C. H. Wang, L. X. Liang, H. Wang, B. Wen, and H. J. Wu, "Function analysis and confirming method of key blasting parameters for excavating in hard rock," Journal of China Coal Society, vol. 40, no. 7, pp. 1526-1533, 2015.

[21] Y. Sun and X. S. Li, "Slant angle and its influence on rock cutting performance," Advances in Civil Engineering, vol. 2018, Article ID 6519029, 11 pages, 2018.

[22] K. Man, X. L Liu, J. Wang, and X. Y. Wang, "Blasting energy analysis of the different cutting methods," Shock and Vibration, vol. 2018, Article ID 9419018, 13 pages, 2018.

[23] C. B. Zhou, "Study on simulation optimization and application of shaft formation by one deep-hole blasting," Wuhan: China University of Geosciences, 2004.

[24] Q. Zong, "Tunneling blasting parameters model experiment study on vertical well freezing soil," Hefei: University of Science and Technology of China, 2004.

[25] S. B. Qin and S. H. Qin, "Study on the similarity of model experiment of underground medium-length-hole blasting," Engineering Blasting, vol. 7, no. 2, pp. 9-11, 2001. 